\title{
An empirical study of
}

\section{factors affecting investors' decisions in the Iranian Stock Market: A combined DEMATEL-ANP approach}

\author{
Shafiee Sardasht, Morteza \\ Moradi, Mohsen \\ Rahmani, Hamed
}

- RECEIVED: 8 feBrUARY 2014

- accepted: II may 2014

\begin{abstract}
Techniques for picking stock are of great importance in stock markets. Identifying stock picking criteria and information required by investors can help investors to make reasoned decisions and perform better than the market average. In this research, a combined approach of Decision Making Trial and Evaluation Laboratory (DEMATEL) and Analytic Network Process (ANP) is conducted based on Iranian brokers' expert opinions, in order to explore factors affecting investors' decisions. This method analyzes interaction levels between factors affecting stock prices in order to structure an investment model that takes these interactions into consideration. The results obtained indicate that political factors have the greatest effect on Iranian investors' decisions, followed by other investors' recommendations and then herd behavior factors. On the contrary, the use of personal and scientific analysis is uncommon.
\end{abstract}

\section{Keywords:}

DEMATEL, ANP, Investment approaches, Experts, Stock Exchange, Iran.

JEL classification:

C53, D53, D81, G11.

Shafiee Sardasht, M. Faculty of Management and Accounting, Islamic Azad University, Mashhad Branch, Mashhad, Iran. O)(98)9155 I 4035 I Fax:( 98)5 I I844862 I.E-mail: Acc.shafiee@gmail.com

Moradi, M. Faculty of Management, University Of Imam Reza, Mashhad, Iran. E-mail: Momoradi2010@yahoo.com

Rahmani, H. Faculty of Management and Accounting, Islamic Azad University, Mashhad Branch, Mashhad, Iran.

E-mail:ham_rahmanil@yahoo.com 


\title{
Un estudio empírico sobre los factores que afectan las decisiones de los inversores en el Mercado de Valores iraní. Un enfoque combinado DEMATEL-ANP
}

\author{
Shafiee Sardasht, Morteza \\ Moradi, Mohsen \\ Rahmani, Hamed
}

\section{Resumen}

El criterio de selección de valores es de gran importancia en los mercados bursátiles. La identificación de los criterios de selección de valores y el tipo de información requerido por los inversores puede ser de gran ayuda para estos a la hora de tomar decisiones razonables y fundamentadas y lograr una eficiencia superior a la media del mercado. En este artículo, se lleva a cabo una combinación de las técnicas DEMATEL (Laboratorio de toma de decisiones y evaluación de pruebas) y ANP (Proceso de Jerarquía Analítica), en base a las percepciones de los brokers iraníes, para explorar los factores que afectan la decisión de los inversores. Dicha combinación analiza los niveles de interacción entre los factores que afectan a los precios de los valores para estructurar un modelo de inversión que los tenga en cuenta. Los resultados obtenidos indican que los factores políticos y las recomendaciones de otros inversores, así como los factores de comportamiento del rebaño, por este orden, son los que más incidencia tienen en las decisiones de los inversores iraníes. Por el contrario, la utilización del análisis personal y científico es poco frecuente.

\section{Palabras clave:}

DEMATEL, ANP, Enfoques de inversión, Expertos, Mercado de Valores, Irán. 


\section{Introduction}

Stock is one of the most important financial assets in capital markets. Factors that can help investors in stock picking are extremely valuable. With respect to the fact that the objective of stock investment is wealth maximization, a successful investor is the person or institution that makes proper decisions about the future of stocks by considering all factors.

It should be noted that decisions should not be made based on only one criterion (factor); several criteria (factors) should be used jointly and simultaneously. Over the past years, financial researchers have used various methods for stock price analysis. Several methods have also been investigated and developed to identify appropriate criteria for picking stocks. In this regard, the role of investment approaches such as fundamental analysis, technical analysis and behavioral finance analysis is to identify and discover key factors that have a significant influence on stock prices. Based on their individual characteristics, each approach contributes factors for stock price prediction. However, the efficiency of factors affecting stock price is often investigated separately and independently from one other in these methods (Lee et al., 2011).

In studies that use the above approaches, the direct and unidirectional effects of each factor on stock prices are often analyzed individually rather than identifying interdependencies. Therefore, these conventional approaches do not provide a proper and direct comparative evaluation of the significance of these factors because they do not conduct quantitative interdependency analysis (Lee et al., 2011). To combat this problem, a combination of Analytic Network Process (ANP) and Decision Making Trial and Evaluation Laboratory (DEMATEL) can be used as Multiple Criteria DecisionMaking (MCDM) methods ( $\mathrm{Li}$ and Tzeng, 2009) to evaluate the interdependencies of factors which influence stock purchase.

ANP is a comprehensive decision-making technique which involves the relationships between existing criteria in the problem. "The ANP provides a general framework to deal with decisions without making assumptions about the independence of higher level elements from lower level elements and about the independence of the elements within a level" (Saaty, 2005). On the other hand, DEMATEL is used to prioritize approaches, criteria and the relationships between them. This technique is a decision-making method based on pairwise comparisons. It uses expert opinions and the Graph theory to provide a hierarchical structure of the factors in a system, showing their mutual impact and influence relationships, in such a way that the intensity of their effect is quantitatively determined. In fact, DEMATEL helps develop a causal structure between factors instead of a direct structure by clarifying relationships (Chen, 2012). 
The purpose of this paper is to provide evidence relating to the application of ANP and DEMATEL on the Iranian stock market. To this end, by conducting the aforementioned combined method, the relationships of interdependencies among key factors in stock investment in the Tehran Stock Exchange (TSE) are analyzed with reference to Iranian brokers' perceptions.

The rest of this paper is organized as follows. The next section provides a review of the theoretical literature. Section 3 presents a brief historical overview. In Section 4, data, processing and methodologies of ANP and DEMATEL are described. This is then followed by the results from the implementation of the combined DEMATEL-ANP methodology. Finally, discussion and conclusions are presented in Section 6.

\section{Theoretical background}

\subsection{Factors affecting investors' decisions}

Numerous factors affect investors' stock purchase decisions. These can be classified into internal and external factors.

Internal factors are directly connected to investors and their psychological and behavioral conditions.

In recent years, financial markets have witnessed sharp fluctuations in stock prices highly influenced by the behavior of investors, their perspectives, insights and experiences of social, economic and political variables. As a result, there is a need to examine psychological patterns and their impact on financial markets. The behavioral finance theory is a new psychological approach for understanding the behaviors of investors and markets.

Many financial and economic theories are based on the hypothesis that individuals act rationally in the face of economic events. Rational decision-making means making the decisions which maximize the chance of achieving the goals and objectives (Pompian, 2006). However, it is necessary to consider the probability that in economics, when trying to find solutions to empirical puzzles, some factors are not fully rational (Brabazon, 2000).

In standard finance theories, investors' behavior and the effect of their personality is assumed to be constant. This approach which is based on "how individuals should behave" is called the normative approach. On the other hand, the behavioral approach identifies cognitive errors and emotions that often affect financial decision- 
makers and result in poor decisions. This approach emphasizes human behavior. In fact, the behavioral finance approach studies "how individuals behave" in a financial context. Therefore, it can be stated that behavioral finance is a combination of classical economics and finance with psychology and decision-making sciences, which seeks to explain financial anomalies (Fuller, 1998).

External factors, unlike internal factors, are indirectly connected to investors, who make decisions by analyzing such factors during stock purchases. External factors include economic, political and military elements, as well as a firm's internal factors:

- Economic factors: If the economy of a country is expected to have reasonable growth for a substantial period of time, this would naturally serve to increase stock price. In countries which benefit from continuous growth and stability, investment in common stock (firms with growth) will be much more efficient compared to other forms of investment and vice versa. It can generally be said that economic factors and associated economic predictions have a significant effect on investors' decision-making as well as type and amount of investment.

- Political and military factors: It has been experimentally proven that Stock Exchanges are characterized by the immediate effect of political issues on exchange transactions. For example, the possibility of the rise to power of an extremist political party opposed to prevailing views on current economic conditions can affect firms' stock price. People's investment incentive is highly dependent on their feelings about capital security and the position of investment in the society. If there is a societal threat which puts capital and investment security in danger, instead of investing in firms' stock, people would invest their capital abroad or in an environment of which they have complete understanding.

- Firms' internal factors: Firms' internal factors include those affecting stock price in connection with operating profits and decisions made. Earnings per share (EPS), price-toearnings ( $P / E)$, benefits, firms' cash flow, banks' tightened monetary policy management and the support tools in the Stock Exchange can all be named as internal factors.

\subsection{Investment approaches}

In the financial literature on stock price analysis and investment in financial assets, three methodologies have been broadly applied: fundamental analysis, technical analysis and behavioral finance. Factors mentioned in the previous section are analyzed here based on these approaches.

Fundamental analysis identifies factors determining the intrinsic value of a financial instrument and decisions are made based on this. P/E, EPS and dividend per share 
(DPS) are among the factors in this category. Fundamental factors are a result of a firm's micro-environment and macro-environment (Xu and Wu, 2006). Therefore, fundamentalists' reactions are based on the analysis of underlying economic conditions (Oberlechner, 2001). Considerable research has been conducted on the advantage of using fundamental analysis techniques to examine stock markets. Research by Campbell (1987), Cochrane (1991), Fama and French (1989), Renshaw (1993), Campbell and Sheller (1988), among many others, indicates that annual and quarterly stock return can be predicted using P/E ratio, stock profit, dividend yield, economic variables and firms' special conditions. Abarbanell and Bushee (1998), Fama and French (2006), Wu and Xu (2006) and Cole et al. (2008) have also emphasized the fundamental approach in their research.

Technical analysis advocates (chartists), believe that the price reflects all the information available in the market. Therefore, stock price and volume data determine future stock price movements (Blume et al., 1994). As a matter of fact, this approach holds that information has already affected price and is based on stock price return and predictability patterns. Indices and patterns used in this approach include simple moving average (SMA), weighted moving average (WMA), exponential moving average (EMA), relative strength index $(\mathrm{RSI})$, commodity channel index $(\mathrm{CCl}), \% \mathrm{~K}$ and $\% \mathrm{D}$ stochastic, Williams \% R (WIL) and money flow index (MFI). Despite chartists' belief in the profitability of this method, extensive research has been conducted on this issue in the past few decades which has yielded contradictory results. Initial studies by Alexander (1961), Fama and Blume (1966), Dryden (1970), Cunningham (1973), Rozeff(1974) and Dann et al. (1977), among others, emphasized the ineffectiveness of technical methods for stock price prediction. Conversely, some studies such as those conducted by Ming-Ming and Siok-Hwa (2006), Ellis and Parbery (2005), Marshall and Cahan (2005), Anderson and Faff (2008), Letamendia (2007), Armano et al. (2005) and Zarandi et al. (2009) emphasize the usefulness of this approach.

As previously mentioned, behavioral finance aims to connect financial science and other social science disciplines. Accordingly, it can be said that personality plays a prominent role in this approach. Decision-making is so intertwined with the decider's psychological characteristics that it is impossible to study the former without taking the latter into account. The importance of the many individual differences between people is that the information needed for decision-making is understood and interpreted with respect to these differences.

Conventional economic theories, such as the modern portfolio theory and the efficient market hypothesis (EMH), do not explain investors' partiality and market irregularity. There are at least five major areas in which neoclassic economic theory cannot explain market results and investors' real behavior. These areas include trad- 
ing volume, capital market volatility, dividends, equity premium puzzle and predictability (Thaler, 1999). Cognitive errors which affect investors' decisions and consequently market results include anchoring, information availability bias, information confirmation bias, disposition effect, framing and reference dependence, illusion of control, optimism bias, overconfidence bias, overreaction, representativeness and underreaction (Flynn, 2008). Considerable research has also been conducted to identify investors' psychological factors including those conducted by Ritter (2003), Shapira and Venezia (2005), Kim and Nofsinger (2007), Wurgler et al. (2010) and Lu et al. (2012).

\section{Historical background}

To forecast future stock prices, fundamental analysis combines analysis of economics, industry, and companies in order to establish a stock's current fair value and forecast future value. Many studies have been conducted according to the fundamental approach. Quirin et al. (2000) surveyed the US oil and gas exploration and production industry and concluded that there is a significant relationship between a number of the fundamentals and both the market value of equity and cumulative stock return. Tang and Shum (2003) documented a significant relationship between political shocks and stock returns. Clubb and Naffi (2007) investigated the fundamental approach with respect to British firms. The results emphasized the significant role of the fundamental approach in the prediction of stock return. Edirisinghe and Zhang (2007a) developed a generalized data envelopment analysis (DEA) model to analyze a firm's financial statements over time in order to determine a relative financial strength indicator (RFSI) that is predictive of the firm's stock price returns. Cole et al. (2008) documented that that stock market index returns affect future economic growth and the two elements also interact. Samaras et al. (2008) adopted the multicriteria decision support system and portfolio management to evaluate the strengths and weaknesses of individual stocks based on the method of fundamental analysis. Yildiz and Yezegel (2010) performed fundamental analysis and cross-sectional prediction of stock return with neural network technology. The results highlighted neural network's ability to predict future returns in NYSE/AMEX/Nasdaq securities for the period 1990-2005.

On the other hand, over the years, many researchers have examined the technical approach. Mizuno et al. (1998) used Japanese stock data and utilized variable length moving average (VMA) and relative strength indicators (RSI) to construct a stock prediction model that yielded empirical findings robust to the alternative methods. Lo $e t$ al. (2000) proposed a systematic and automatic approach to technical pattern recognition using nonparametric kernel regression, and applied the proposed method to a large number of U.S. stocks from 1962 to 1996. The findings showed over the 31-year 
sample period, several technical indicators provide incremental information. In their study of Microsoft, Intel, and IBM, Wang and Chan (2006) employed decision trees integrated with RSI to study timing points of stock purchase. The research showed this method can accurately predict optimal buying timing and enhance investors' returns. Liu and et al. (2007) examined the use of technical analysis and the PXtract algorithm in predicting stock prices in the Hong Kong stock market. The results showed that the PXtract algorithm in combination with technical analysis can predict stock price movements. Groenewold et al. (2008) investigated the efficiency of technical analysis methods. Nguyen and Chen (2008) researched institutional investors' herd behavior and its effect on stock prices. They cited the reason for their study as the fact that when institutional investors become the main players in the capital market, their herd behavior may result in stock price volatility and consequently return volatility. Rosillo et al. (2013) examined the result of the application of the RSI, Moving Average Convergence Divergence (MACD), Momentum and Stochastic indicators in different companies of the Spanish continuous market. They used these indicators to give purchase and sale recommendations to small investors.

While conventional academic finance emphasizes theories such as the modern portfolio theory and the efficient market hypothesis, the emerging field of behavioral finance investigates the psychological and sociological issues that impact the decision-making process. Many studies have examined the behavior of investors and its impact on the way they purchase and sell stock. For example Daniel et al. (1998) presented a model in which investors underreact to public signals, motivated by different psychological biases. They predicted that prices would overreact to private signals but underreact to public ones. Shefrin (2000) described behavioral finance as the interaction of psychology with the financial actions and performance of practitioners (all types/categories of investors). He recommended that these investors should be aware of their own investment mistakes as well the errors of judgment of their counterparts. Caparrelli et al. (2004) studied the herding effect in the capital markets by using data from the Italian Stock Exchange. They concluded that herding can be observed in extreme market conditions. Kothari et al. (2006) studied the stock market reaction to aggregate earnings news. They found that the relation between returns and earnings is substantially different in aggregate data. Cheng (2007) suggested that overconfidence behavior is the most common human characteristics, reflecting a tendency to overestimate ability, chances for success and the probability that someone will gain positive outcomes, and the accuracy of the knowledge possessed. Hoffmann et al. (2012) examined behavioral aspects (framing, risk aversion) of Covered Call Writing. They found highly significant empirical evidence for a pronounced framing effect with respect to different covered call designs with equal net cash flows as well as covered calls in general. They also highlighted the limited amount of empirical evidence demonstrating a relationship between risk aversion in the domain of gains and a preference for covered calls. 
Previous research has focused on all factors related to fundamental, technical and behavioral approaches separately and independently of other factors. Similarly, the influence of each factor in investors' decisions is individually studied and determined. Consequently, the interdependent relationships between factors are not considered in these approaches.

As mentioned previously, this research applies the DEMATEL and ANP methods to analyze approaches and factors affecting investors' investment and stock purchasing decisions by focusing on the relationships between these factors. A number of studies have provided evidence of the interdependent relationship using DEMATEL and ANP. Cheng and Li (2007) used ANP to determine key selection criteria for a strategic partner and additionally to identify the relative importance among the criteria. Ou Yang et al. (2008) proposed the application of both DEMATEL and ANP methods as the hybrid MCDM model. Tsai and Chou (2009) applied a hybrid model based on DEMATEL, ANP, and zero-one goal programming (ZOGP) to selecting management systems for sustainable development in small and medium enterprises (SMEs). Lee et al. (2011) have studied decision making factors for equity investment by DEMATEL and ANP. The empirical results showed that factors from the fundamental analysis, technical analysis, and institutional investor analysis methodologies had significant interactive and self-feedback dynamics. Among the key factors affecting investment decision, profitability was the most important, followed by growth and trading volume. Additional recent studies that use DEMATEL and ANP include Yang and Tzeng (2011), Büyüközkan and Çifçi (2012), Wang and Tzeng (2012), however, no existing studies provide evidence on the interdependent relationship between the factors across all three of the fundamental, technical and behavioral approaches.

\section{Case study: data, processing and methods}

The case study of this research is TSE, which is an emerging market. Emerging market economies are very different from advanced economies and this needs to be considered when designing policies (Mishkin, 2004). More specifically, as stated above, this article seeks to determine what factors affect Iranian investors' stock purchases and how the hierarchy of these factors affects investors' stock choices.

To conduct the study, after compiling potential factors influencing stock choice, the opinions of expert regarding these factors were applied to DEMATEL. The statistical sample of the majority of DEMATEL-based research is composed of about 10 to 12 selected experts. However, up to 20 participants are used in some research. It should be noted that the quality of expert opinion is key. In this research we used the opinions 
of 25 investment experts. Research samples are selected based on features such as investment experience and familiarity with the factors being analyzed.

25 questionnaires (see Appendix A) were handed out to the certified brokers at the TSE in August and September 2012. As stated above, brokers were selected principally on the basis of their relationship with a wide range of stock purchasers in the TSE and their comprehensive familiarity with their processes of investment. Potential and operative factors in investors' decision to purchase stock were determined according to research literature, desk study and the opinion of financial experts. Afterwards, factors were classified and pairwise comparison questionnaires were prepared. In order to confirm the questionnaire's validity, a number of brokers and experts gave their opinions on the identified factors, which ultimately led to some modifications being made. Also, the questionnaire's reliability was evaluated using the consistency rate (CR).

In regard to the methodology, the combination of DEMATEL and ANP proposed by Yang et al. (2008) is used to prioritize the factors affecting stock purchasers in Iran.

ANP is a developed form of the Analytic Hierarchy Process (AHP) method. The AHP methodology, which was developed by Saaty (1980), is a powerful tool in solving decision problems (Sevkli et al., 2008). The basic assumption of this technique is that relations between decision levels are unidirectional and hierarchical. It means that each decision level is only dependent on the level immediately above it. Thus, AHP ignores the relationship between criteria in the relevant problem.

Whereas AHP represents a framework with a unidirectional hierarchical relationship, ANP allows for more complex interrelationships among decision levels and attributes. This process provides a way to input judgments and measurements to derive ratio scale priorities for the distribution of influence among the factors and groups of factors in the decision (Saaty, 2003).

By replacing hierarchy with network, the ANP models the problem using a feedback approach. In a network, there may be source nodes, intermediate nodes and lower nodes. In this method, the interdependency between two nodes is called outer dependency and the dependency between elements in a node is called inner dependency. Appendix B summarizes some definitions and properties of AHP and ANP.

The ANP has been successfully applied in many fields, however, ANP studies deal imperfectly and incompletely with inner dependences. In such cases, the DEMATEL can not only convert the relationships between cause and effect of criteria into a visual structural model, but it can also be used as a practical way to handle the inner dependences within a set of criteria (Chung et al., 2005). In other words, this method, 
which was developed by the Science and Human Affairs Program of the Battelle Memorial Institute of Geneva between 1972 and 1976, can convert the relationship between the causes and effects of criteria into an intelligible structural model of the system. Appendix C also summarizes some definitions and properties of DEMATEL. In an integrated approach, the ANP model is used to calculate the weights of elements of evaluation clusters and the DEMATEL is used to analyze inner dependences within an evaluation cluster.

\section{Results from the implementation of the combined DEMATEL-ANP methodology}

The following steps were followed to implement the combined method:

Step 1: A list of potential factors affecting investors' decision was drawn up. Thus, within the context of the capital market in Iran, 29 key factors were selected. After classifying the factors, a network was prepared consisting of 4 levels including purpose (rating of effective factors), approaches (technical, fundamental and behavioral approaches), criteria (15 criteria) and sub-criteria (18 sub-criteria). The key factors are shown in Table 1.

\section{Table 1. Key factors in stock investment decision-making}

\begin{tabular}{|c|c|c|c|}
\hline Approaches & Criteria & Sub-criteria & Some of Related Studies (Sources) \\
\hline \multirow{11}{*}{ 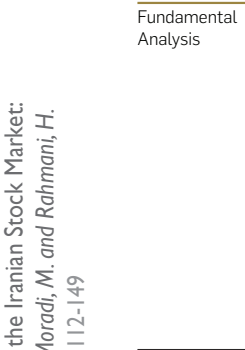 } & \multirow[t]{5}{*}{ Ratio analysis } & DPS & Al-Tamimi (2006), Hartono (2004) \\
\hline & & EPS & Al-Tamimi (2006) \\
\hline & & P/E & Squyres (1998), Beckwith (2001) \\
\hline & & ROE & Edirisinghe and Zhang (2007b) \\
\hline & & MV/BV & Al-Tamimi (2006), Beckwith (2001) \\
\hline & \multicolumn{2}{|l|}{ Market status } & Experts view \\
\hline & \multicolumn{2}{|l|}{\begin{tabular}{|l} 
Economic analysis of industry \\
\end{tabular}} & Experts view \\
\hline & \multicolumn{2}{|l|}{\begin{tabular}{|l} 
Equity analysis \\
\end{tabular}} & Experts view \\
\hline & \multicolumn{2}{|l|}{ Capital raising } & Brav et al. (2000) \\
\hline & \multicolumn{2}{|l|}{ Majority ownership type } & Experts view \\
\hline & \multicolumn{2}{|l|}{ Profitability and Future growth } & Al-Tamimi (2006), Lee et al. (2011) \\
\hline \multirow{10}{*}{ 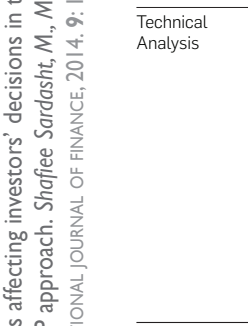 } & \multirow[t]{5}{*}{ Moving average } & SMA & \multirow{5}{*}{$\begin{array}{l}\text { Gunasekarage et al. (2001) } \\
\text { Hudson and et al. (1996), Brock et al. (1992 } \\
\text { Levich and Thomas (1993), Kho (1996) } \\
\text { Wong et al. (2003) } \\
\text { Tanaka-Yamawaki and Tokuoka (2007) } \\
\text { Zarandi et al. (2009) }\end{array}$} \\
\hline & & WMA & \\
\hline & & EMA & \\
\hline & & VMA & \\
\hline & & TMA & \\
\hline & \multicolumn{2}{|l|}{ Price trend } & Blume (1978) \\
\hline & \multicolumn{2}{|l|}{\begin{tabular}{|l|} 
Relative strength index \\
\end{tabular}} & Wong et al.(2003) \\
\hline & \multicolumn{2}{|l|}{ Trading volume } & Kalev (2002), Huddart (2003) \\
\hline & \multicolumn{2}{|l|}{ Head and shoulders } & Savin (2007), Osler and Chang (1995) \\
\hline & \multicolumn{2}{|l|}{\begin{tabular}{|l|} 
Symmetrical triangles \\
\end{tabular}} & Edwards et al. (2012) \\
\hline \multirow{8}{*}{ 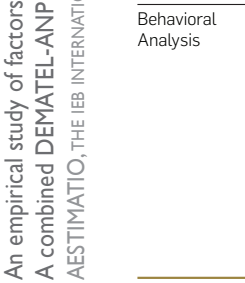 } & \multirow[t]{3}{*}{ Psychological factors } & Overconfidence & Glaser and Weber (2003), Biais et al. (2002) \\
\hline & & Past stock price & Huddart (2003) \\
\hline & & Risk-seeking & $\begin{array}{l}\text { Girard and Omran (2007), Tang and Shum } \\
\text { (2003), Lee et al. (2011) }\end{array}$ \\
\hline & \multirow[t]{5}{*}{\begin{tabular}{|l} 
Societal factors \\
\end{tabular}} & Institutional investors & Hirose et al. (2009) \\
\hline & & Rumors & Hunton et al. (2001) \\
\hline & & Herd behavior & Chang et al. (2000),Tan et al. (2008) \\
\hline & & Political factors & Wisniewski (2009) \\
\hline & & Investors' recommendations & Barber et al. (2001), Lee et al. (2011) \\
\hline
\end{tabular}


Step 2: With regard to the questionnaires, collected matrices and also the Majority rule, the relationships between approaches, criteria and sub-criteria were identified and the mean of scores given to them by experts (brokers) was calculated. A diagram of the relationships, based on the data from pairwise comparisons and also the mean, is shown in Figure 1.

Figure 1. The relationships between approaches, criteria and sub-criteria
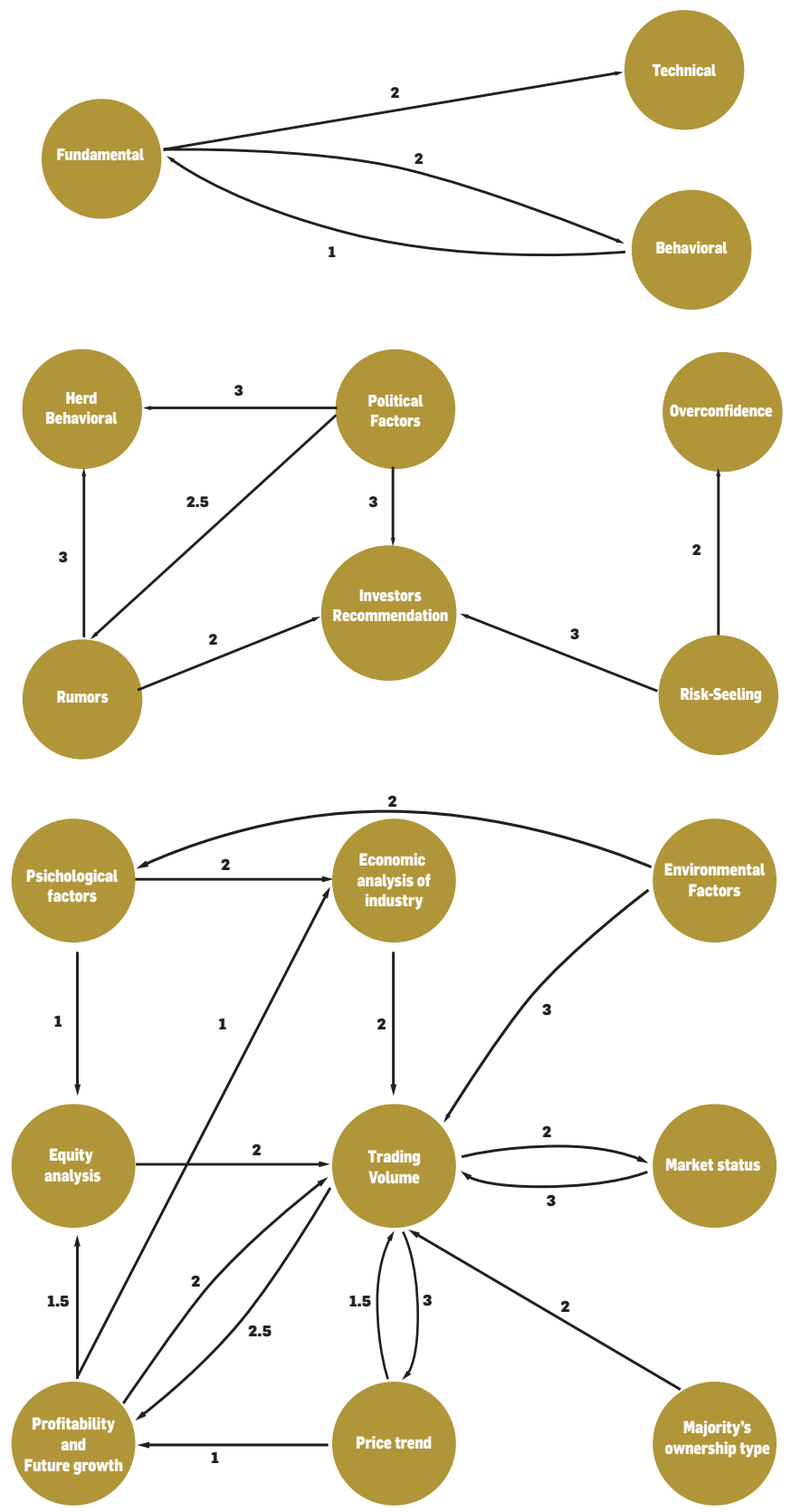
Step 3: The direct-relation matrix $\mathbf{Z}$, for the Iranian case under study, is prepared with regard to the relationships and the mean of scores obtained in the previous step. The direct-relation matrix is an $n \times n$ (here $3 \times 3$ ) matrix, in which $z_{i j}$ denotes the degree to which the criterion $i$ affects the criterion $j$ (Table 2).

\section{Table 2. The direct-relation matrix}

\begin{tabular}{lcccc}
\hline & Fundamental & Technical & Behavioral & \\
\hline Fundamental & 0 & 2 & 2 & $\mathbf{4}$ \\
\hline Technical & 0 & 0 & 0 & $\mathbf{0}$ \\
\hline Behavioral & 1 & 0 & 0 & $\mathbf{1}$ \\
\hline
\end{tabular}

Next, the normalized direct-relation matrix $\mathbf{X}$ is calculated at the approaches level as follows (since all the calculations of approach, criteria and sub-criteria levels cannot be shown, only the calculations and Tables of the approach level are described as an example):

$$
\mathbf{X}=s \times \mathbf{Z},
$$

where

$$
s=\min \left[\frac{1}{\max \sum_{j=1}^{n}\left|z_{i j}\right|}, \frac{1}{\max \sum_{i=1}^{n}\left|z_{i j}\right|}\right], \quad i, j=1,2, \ldots ., n .
$$

Since from matrix $\mathbf{Z}$ it can be deduced that

$$
\begin{gathered}
\max \sum_{i=1}^{n}\left|z_{i j}\right|=\max [1,2,2]=2 \\
\max \sum_{j=1}^{n}\left|z_{i j}\right|=\max [4,0,1]=4 \\
s=\min \left[\frac{1}{\max \sum_{j=1}^{n}\left|z_{i j}\right|}, \frac{1}{\max \sum_{i=1}^{n}\left|z_{i j}\right|}\right]=1 / 2,
\end{gathered}
$$

the normalized direct-relation matrix $\mathbf{X}$ at the approach level for the Iranian case under study is produced as shown in Table 3.

\section{Table 3. The Normalized direct-relation matrix}

\begin{tabular}{lccc}
\hline & Fundamental & Technical & Behavioral \\
\hline Fundamental & 0 & 0.5 & 0.5 \\
\hline Technical & 0 & 0 & 0 \\
\hline Behavioral & 0.25 & 0 & 0 \\
\hline
\end{tabular}


Step 4: The Total-relation matrix $\mathbf{T}$ (Table 4), which indicates the relative degree of direct and indirect relationships between approaches, criteria and sub-criteria, is calculated by:

$$
\mathbf{T}=\mathbf{X}(\mathbf{I}-\mathbf{X})^{-1}
$$

\section{Table 4. The Total-relation matrix at the level of approaches}

\begin{tabular}{lccc}
\hline & Fundamental & Technical & Behavioral \\
\hline Fundamental & 0.143 & 0.571 & 0.571 \\
\hline Technical & 0 & 0 & 0 \\
\hline Behavioral & 0.286 & 0.143 & 0.143 \\
\hline
\end{tabular}

Step 5: To determine the weights of elements, the ANP uses the supermatrix method. A supermatrix is in fact a partitioned matrix in which each part of the matrix shows the relationship between two nodes (decision levels) in the overall decision problem. This matrix can limit coefficients for calculating all the priorities and thus determine the aggregate effect of each element on other elements.

The initial supermatrix should be provided prior to the implementation of ANP. If the weighted supermatrix on the main diagonal is not zero in the initial supermatrix, there would be internal relationship networks between their components. Zero entries in weighted matrices indicate that there are no relationships between the components. With regard to the explanations above and also the equations obtained in step 2, the initial supermatrix based on the study's network structure is provided (see Figure 2). $\mathbf{W}_{\mathbf{2 1}}$ in Figure 2 indicates the weighted vector of approaches based on the objective function without taking into account the internal relationships between them, which are obtained by comparisons in the ANP method. The total-relation matrix of approaches and criteria are placed in entries $\mathbf{W}_{\mathbf{2} 2}$ and $\mathbf{W}_{\mathbf{3 3}}$. These weights are placed on the main diagonal of the supermatrix and show the internal relationships between criteria. Pairwise comparison of criteria is conducted with regard to the approaches and the weight vectors of these comparisons are placed in the entry $\mathbf{W}_{32}$ of the supermatrix. It should be noted that the entries of $\mathbf{W}_{\mathbf{2 2}}$ and $\mathbf{W}_{33}$ are at the levels of approaches and criteria based on the total-relation matrix of DEMATEL; and the entries of $\mathbf{W}_{21}$ and $\mathbf{W}_{32}$ are calculated using AHP and the data from the first part of the questionnaire.

Step 6: In this step, the total-relation matrix of approach and also criteria levels is linearly normalized. The resulting matrices are the normalized total-relation matrices of approaches and criteria that are placed in $\mathbf{W}_{22}$ and $\mathbf{W}_{33}$ entries, respectively. The normalized total-relation matrices are inserted into the initial supermatrix. Figure 3 
shows the initial supermatrix after inserting the internal relationships of approaches and criteria.

Then the pairwise comparison of approaches is conducted based on the objective function without taking the internal relationships between them into account. The result is presented in Table 5. The normalized weight vector resulting from these pairwise comparisons is placed in the supermatrix in the $\mathbf{W}_{\mathbf{2 1}}$ entry (Figure 4 ). It should be noted that these results are calculated with regard to the opinions collected in the second part of the questionnaire. The shaded area in Figure 3 indicates the geometric mean obtained from these opinions.

\section{Figure 2. Initial supermatrix based on network structure}

\begin{tabular}{|c|c|c|c|c|c|c|c|c|c|c|c|c|c|c|c|c|c|c|c|c|}
\hline & & \multicolumn{3}{|c|}{ Approaches } & \multicolumn{15}{|c|}{ Criteria } \\
\hline & & $\begin{array}{l}\text { : } \\
\text { 产 } \\
\text { 言 }\end{array}$ & 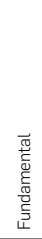 & 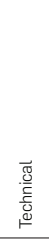 & 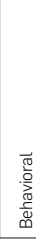 & 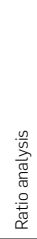 & 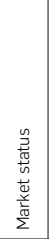 & 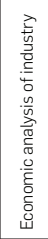 & 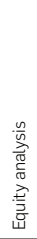 & 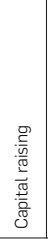 & 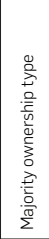 & 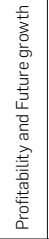 & 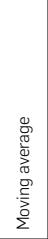 & 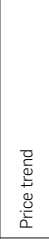 & 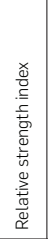 & 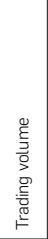 & 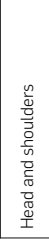 & 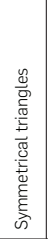 & 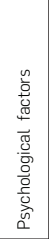 & 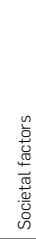 \\
\hline & Purpose & 0 & 0 & 0 & 0 & 0 & 0 & 0 & 0 & 0 & 0 & 0 & 0 & 0 & 0 & 0 & 0 & 0 & 0 & 0 \\
\hline \multirow[b]{3}{*}{$\frac{a}{8}$} & Fundamental & \multirow{3}{*}{$w_{21}$} & \multirow{3}{*}{\multicolumn{3}{|c|}{$\mathbf{w}_{22}$}} & 0 & 0 & 0 & 0 & 0 & 0 & 0 & 0 & 0 & 0 & 0 & 0 & 0 & 0 & 0 \\
\hline & Technical & & & & & 0 & 0 & 0 & 0 & 0 & 0 & 0 & 0 & 0 & 0 & 0 & 0 & 0 & 0 & 0 \\
\hline & Behavioral & & & & & 0 & 0 & 0 & 0 & 0 & 0 & 0 & 0 & 0 & 0 & 0 & 0 & 0 & 0 & 0 \\
\hline \multirow{15}{*}{$\frac{\omega}{\frac{\omega}{\omega}}$} & Ratio analysis & 0 & \multirow{15}{*}{\multicolumn{3}{|c|}{$w_{32}$}} & & & & & & & & \multirow{15}{*}{\multicolumn{2}{|c|}{$\mathbf{w}_{33}$}} & & & & & & \\
\hline & Market status & 0 & & & & & & & & & & & & & & & & & & \\
\hline & Economic analysis of industry & 0 & & & & & & & & & & & & & & & & & & \\
\hline & Equity analysis & 0 & & & & & & & & & & & & & & & & & & \\
\hline & Capital raising & 0 & & & & & & & & & & & & & & & & & & \\
\hline & Majority ownership type & 0 & & & & & & & & & & & & & & & & & & \\
\hline & \begin{tabular}{|l} 
Profitability and Future growth \\
\end{tabular} & 0 & & & & & & & & & & & & & & & & & & \\
\hline & Moving average & 0 & & & & & & & & & & & & & & & & & & \\
\hline & Price trend & 0 & & & & & & & & & & & & & & & & & & \\
\hline & Relative strength index & 0 & & & & & & & & & & & & & & & & & & \\
\hline & \begin{tabular}{|l|} 
Trading Volume \\
\end{tabular} & 0 & & & & & & & & & & & & & & & & & & \\
\hline & Head and shoulders & 0 & & & & & & & & & & & & & & & & & & \\
\hline & Symmetrical triangles & 0 & & & & & & & & & & & & & & & & & & \\
\hline & \begin{tabular}{|l} 
Psychological factors \\
\end{tabular} & 0 & & & & & & & & & & & & & & & & & & \\
\hline & \begin{tabular}{|l} 
Societal factors \\
\end{tabular} & 0 & & & & & & & & & & & & & & & & & & \\
\hline
\end{tabular}


Figure 3. The initial supermatrix after inserting the internal relationships of approaches and criteria

\begin{tabular}{|c|c|c|c|c|c|c|c|c|c|c|c|c|c|c|c|c|c|c|c|c|}
\hline & & \multicolumn{3}{|c|}{ Approaches } & \multicolumn{15}{|c|}{ Criteria } \\
\hline & & $\begin{array}{l}\text { 心 } \\
\text { o } \\
\text { 옴 }\end{array}$ & 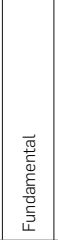 & 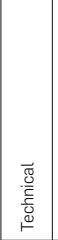 & 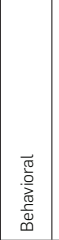 & 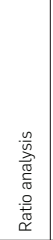 & 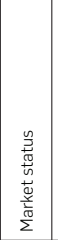 & 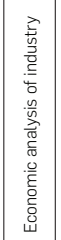 & 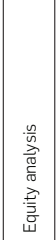 & 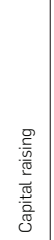 & 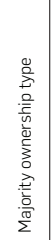 & 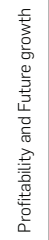 & 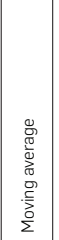 & 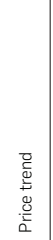 & 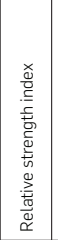 & 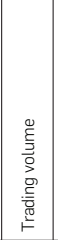 & 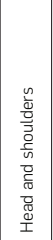 & 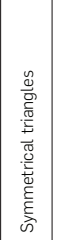 & 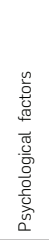 & 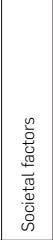 \\
\hline & Purpose & 0 & 0 & 0 & 0 & 0 & 0 & 0 & 0 & 0 & 0 & 0 & 0 & 0 & 0 & 0 & 0 & 0 & 0 & 0 \\
\hline \multirow{3}{*}{ 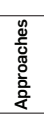 } & Fundamental & \multirow{3}{*}{$w_{21}$} & 0.111 & \begin{tabular}{|l|l|}
0.444 \\
\end{tabular} & \begin{tabular}{|l|l|}
0.444 \\
\end{tabular} & 0 & 0 & 0 & 0 & 0 & 0 & 0 & 0 & 0 & 0 & 0 & 0 & 0 & 0 & 0 \\
\hline & Technical & & 0.000 & 0.000 & 0.000 & 0 & 0 & 0 & 0 & 0 & 0 & 0 & 0 & 0 & 0 & 0 & 0 & 0 & 0 & 0 \\
\hline & Behavioral & & 0.500 & 0.250 & \begin{tabular}{|l|}
0.250 \\
\end{tabular} & 0 & 0 & 0 & 0 & 0 & 0 & 0 & 0 & 0 & 0 & 0 & 0 & 0 & 0 & 0 \\
\hline \multirow{15}{*}{ 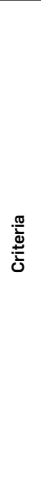 } & Ratio analysis & 0 & \multirow{15}{*}{ 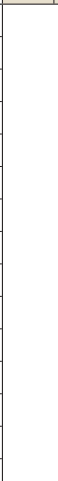 } & \multirow{15}{*}{\multicolumn{2}{|c|}{$\mathbf{w}_{32}$}} & 0.000 & \begin{tabular}{|l|l|}
0.000 \\
\end{tabular} & 0.000 & 0.000 & 0.000 & 0.000 & 0.000 & \begin{tabular}{|l|l|}
0.000 \\
\end{tabular} & 0.000 & \begin{tabular}{|l|}
0.000 \\
\end{tabular} & 0.000 & 0.000 & \begin{tabular}{|l|l|}
0.000 \\
\end{tabular} & 0.000 & 0.000 \\
\hline & Market status & 0 & & & & 0.000 & \begin{tabular}{|l|l|}
0.085 \\
\end{tabular} & 0.006 & 0.009 & 0.000 & 0.000 & 0.113 & \begin{tabular}{|l|l|}
0.000 \\
\end{tabular} & 0.129 & \begin{tabular}{|l|l|}
0.000 \\
\end{tabular} & 0.657 & 0.000 & \begin{tabular}{|l|l|}
0.000 \\
\end{tabular} & 0.000 & 0.000 \\
\hline & Economic analysis of industry & 0 & & & & 0.000 & 0.085 & 0.009 & 0.009 & 0.000 & 0.000 & 0.113 & 0.000 & 0.127 & 0.000 & 0.656 & 0.000 & 0.000 & 0.000 & 0.000 \\
\hline & Equity analysis & 0 & & & & 0.000 & 0.085 & 0.009 & 0.009 & 0.000 & 0.000 & 0.113 & 0.000 & 0.127 & 0.000 & 0.656 & 0.000 & 0.000 & 0.000 & 0.000 \\
\hline & Capital raising & 0 & & & & 0.000 & 0.000 & 0.000 & 0.000 & 0.000 & 0.000 & 0.000 & 0.000 & 0.000 & 0.000 & 0.000 & 0.000 & 0.000 & 0.000 & 0.000 \\
\hline & Majority ownership type & 0 & & & & 0.000 & 0.085 & 0.009 & 0.009 & 0.000 & 0.000 & 0.113 & 0.000 & 0.127 & 0.000 & 0.656 & 0.000 & 0.000 & 0.000 & 0.000 \\
\hline & Profitability and Future growth & 0 & & & & 0.000 & 0.051 & 0.164 & 0.245 & 0.000 & 0.000 & 0.069 & 0.000 & 0.076 & 0.000 & 0.395 & 0.000 & 0.000 & 0.000 & 0.000 \\
\hline & Moving average & 0 & & & & 0.000 & 0.000 & 0.000 & 0.000 & 0.000 & 0.000 & 0.000 & 0.000 & 0.000 & 0.000 & 0.000 & 0.000 & 0.000 & 0.000 & 0.000 \\
\hline & \begin{tabular}{|l|} 
Price trend \\
\end{tabular} & 0 & & & & 0.000 & 0.060 & \begin{tabular}{|l|}
0.024 \\
\end{tabular} & 0.032 & 0.000 & 0.000 & 0.339 & 0.000 & 0.088 & 0.000 & 0.458 & 0.000 & 0.000 & 0.000 & 0.000 \\
\hline & Relative strength index & 0 & & & & 0.000 & 0.000 & 0.000 & 0.000 & 0.000 & 0.000 & 0.000 & \begin{tabular}{|l|}
0.000 \\
\end{tabular} & 0.000 & 0.000 & 0.000 & 0.000 & 0.000 & 0.000 & 0.000 \\
\hline & Trading Volume & 0 & & & & 0.000 & \begin{tabular}{|l|}
0.217 \\
\end{tabular} & \begin{tabular}{|l|}
0.019 \\
\end{tabular} & 0.028 & 0.000 & 0.000 & 0.292 & \begin{tabular}{|l|}
0.000 \\
\end{tabular} & 0.327 & 0.000 & 0.117 & 0.000 & 0.000 & 0.000 & 0.000 \\
\hline & Head and shoulders & 0 & & & & 0.000 & 0.000 & 0.000 & 0.000 & 0.000 & 0.000 & 0.000 & 0.000 & 0.000 & 0.000 & 0.000 & 0.000 & 0.000 & 0.000 & 0.000 \\
\hline & Symmetrical triangles & 0 & & & & 0.000 & 0.000 & 0.000 & 0.000 & 0.000 & 0.000 & 0.000 & 0.000 & 0.000 & 0.000 & 0.000 & 0.000 & 0.000 & 0.000 & 0.000 \\
\hline & Psychological factors & 0 & & & & 0.000 & \begin{tabular}{|l|l|}
0.013 \\
\end{tabular} & \begin{tabular}{|l|l|}
0.551 \\
\end{tabular} & 0.278 & 0.000 & 0.000 & 0.021 & 0.000 & 0.021 & 0.000 & 0.115 & 0.000 & 0.000 & 0.000 & 0.000 \\
\hline & Societal factors & 0 & & & & 0.000 & \begin{tabular}{|l|l|}
0.057 \\
\end{tabular} & \begin{tabular}{|l|}
0.040 \\
\end{tabular} & 0.025 & 0.000 & 0.000 & 0.078 & \begin{tabular}{|l|}
0.000 \\
\end{tabular} & 0.086 & \begin{tabular}{|l|l|}
0.000 \\
\end{tabular} & 0.444 & 0.000 & \begin{tabular}{|l|l|}
0.000 \\
\end{tabular} & 0.270 & \begin{tabular}{|l}
0.000 \\
\end{tabular} \\
\hline
\end{tabular}

Table 5. The pairwise comparisons of approaches without taking the internal relationships between them into account

\begin{tabular}{lcccc}
\hline & Fundamental & Technical & Behavioral & Normalized weight vector \\
\hline Fundamental & 1 & 1.9 & 1.21 & 0.43 \\
\hline Technical & 0.53 & 1 & 1.24 & 0.28 \\
\hline Behavioral & 0.83 & 0.81 & 1 & 0.29 \\
\hline & & & & $\mathbf{C R}=\mathbf{0 . 0 4}$
\end{tabular}

$* C R:$ Consistency rate

It should be noted that the results of pairwise comparisons of consistency are analyzed via CR. When CR is greater than 0.1 for each pairwise comparison matrix, assigned comparisons and weights are inconsistent with each other. Inconsistent results should be immediately modified. Thus, the vector of normalized relative weights for the pairwise comparison of criteria to approaches (Fundamental, Technical and Behavioral) are calculated and placed in $\mathbf{W}_{11}$ and $\mathbf{W}_{\mathbf{3 2}}$ entries, respectively (Figure 5).

Results obtained from the normalized total-relation matrix and normalized weight priority vector are complementary. They generally indicate the purity of the effects 
related to approaches' pairwise comparisons (according to the objective function) and criteria (according to approaches). These results are respectively calculated based on the existence of assumptions for relationship between factors and ignoring the relationship between them.

Therefore, the results of both methods are integrated and shown in Figure 6 . The unweighted supermatrix of approaches and unweighted supermatrix are obtained by integrating normalized total-relation matrix and normalized weight vectors, respectively.

In the final step, the weighted supermatrix is obtained by multiplying the unweighted supermatrix of criteria by the unweighted supermatrix of approaches. The sum of the entries in each column of the weighted matrix should be 1 for the calculation of limited matrices. They are calculated using columnar normalization. The result is shown in Figure 7.

The limited supermatrix (final weight) was calculated using Super Decision 2.2 to determine the priority of approaches and criteria. The results are presented in Table 6.

Figure 4. The initial supermatrix after inserting the normalized relative weight vector of approaches

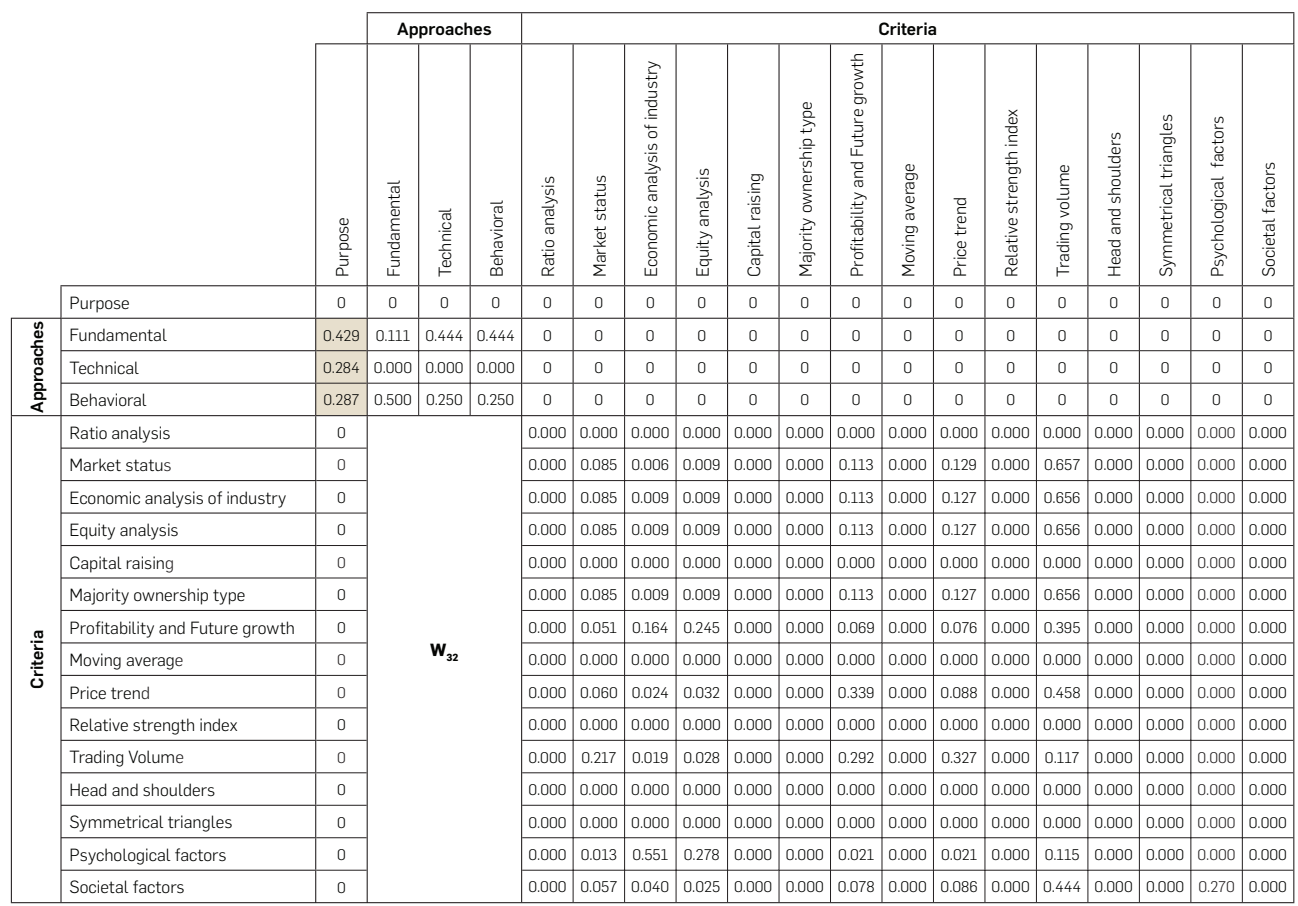


Figure 5. Supermatrix (before the combining of the results of both methods)

\begin{tabular}{|c|c|c|c|c|c|c|c|c|c|c|c|c|c|c|c|c|c|c|c|c|}
\hline & & \multicolumn{3}{|c|}{ Approaches } & \multicolumn{15}{|c|}{ Criteria } \\
\hline & & 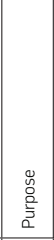 & 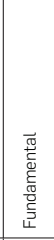 & 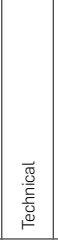 & 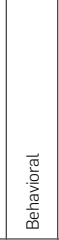 & 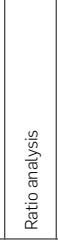 & 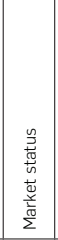 & 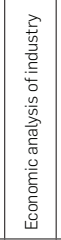 & 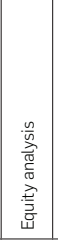 & 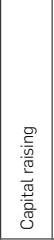 & 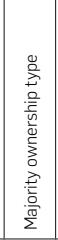 & 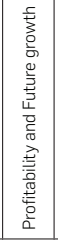 & 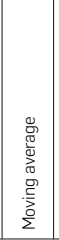 & 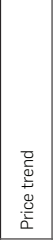 & 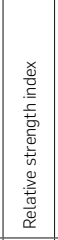 & 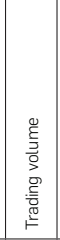 & 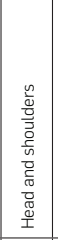 & 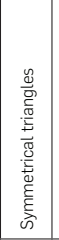 & 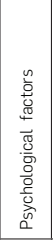 & 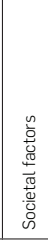 \\
\hline & \begin{tabular}{|l|} 
Purpose \\
\end{tabular} & 0 & 0 & 0 & 0 & 0 & 0 & 0 & 0 & 0 & 0 & 0 & 0 & 0 & 0 & 0 & 0 & 0 & 0 & 0 \\
\hline \multirow{3}{*}{ 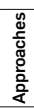 } & Fundamental & 0.429 & 0.111 & \begin{tabular}{|l|}
0.444 \\
\end{tabular} & 0.444 & 0 & 0 & 0 & 0 & 0 & 0 & 0 & 0 & 0 & 0 & 0 & 0 & 0 & 0 & 0 \\
\hline & Technical & 0.284 & 0.000 & 0.000 & 0.000 & 0 & 0 & 0 & 0 & 0 & 0 & 0 & 0 & 0 & 0 & 0 & 0 & 0 & 0 & 0 \\
\hline & Behavioral & 0.287 & 0.500 & \begin{tabular}{|l|}
0.250 \\
\end{tabular} & 0.250 & 0 & 0 & 0 & 0 & 0 & 0 & 0 & 0 & 0 & 0 & 0 & 0 & 0 & 0 & 0 \\
\hline \multirow{15}{*}{ 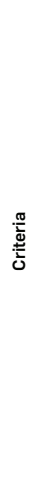 } & Ratio analysis & 0 & 0.060 & 0.000 & 0.000 & 0.000 & 0.000 & 0.000 & 0.000 & 0.000 & 0.000 & 0.000 & 0.000 & 0.000 & 0.000 & 0.000 & 0.000 & 0.000 & 0.000 & 0.000 \\
\hline & Market status & 0 & 0.290 & 0.000 & 0.000 & 0.000 & 0.085 & 0.006 & 0.009 & 0.000 & 0.000 & 0.113 & 0.000 & \begin{tabular}{|l|l} 
\\
\end{tabular} & 0.000 & 0.657 & 0.000 & 0.000 & 0.000 & 0.000 \\
\hline & Economic analysis of industry & 0 & 0.130 & 0.000 & 0.000 & 0.000 & 0.085 & 0.009 & 0.009 & 0.000 & 0.000 & 0.113 & 0.000 & 0.127 & 0.000 & 0.656 & 0.000 & 0.000 & 0.000 & 0.000 \\
\hline & Equity analysis & 0 & 0.099 & 0.000 & 0.000 & 0.000 & 0.085 & 0.009 & 0.009 & 0.000 & 0.000 & 0.113 & 0.000 & 0.127 & 0.000 & 0.656 & 0.000 & 0.000 & 0.000 & 0.000 \\
\hline & Capital raising & 0 & 0.098 & 0.000 & 0.000 & 0.000 & 0.000 & 0.000 & 0.000 & 0.000 & 0.000 & 0.000 & 0.000 & 0.000 & 0.000 & 0.000 & 0.000 & 0.000 & 0.000 & 0.000 \\
\hline & Majority ownership type & 0 & 0.080 & 0.000 & 0.000 & 0.000 & 0.085 & 0.009 & 0.009 & 0.000 & 0.000 & 0.113 & 0.000 & 0.127 & 0.000 & 0.656 & 0.000 & 0.000 & 0.000 & 0.000 \\
\hline & Profitability and Future growth & 0 & 0.241 & 0.000 & 0.000 & 0.000 & 0.051 & 0.164 & 0.245 & 0.000 & 0.000 & 0.069 & 0.000 & 0.076 & 0.000 & 0.395 & 0.000 & 0.000 & 0.000 & 0.000 \\
\hline & Moving average & 0 & 0.000 & 0.107 & 0.000 & 0.000 & 0.000 & 0.000 & 0.000 & 0.000 & 0.000 & 0.000 & 0.000 & 0.000 & 0.000 & 0.000 & 0.000 & 0.000 & 0.000 & 0.000 \\
\hline & Price trend & 0 & 0.000 & 0.231 & 0.000 & 0.000 & 0.060 & 0.024 & 0.032 & 0.000 & 0.000 & 0.339 & 0.000 & 0.088 & 0.000 & 0.458 & 0.000 & 0.000 & 0.000 & 0.000 \\
\hline & Relative strength index & 0 & 0.000 & 0.154 & 0.000 & 0.000 & 0.000 & 0.000 & 0.000 & 0.000 & 0.000 & 0.000 & 0.000 & 0.000 & 0.000 & 0.000 & 0.000 & 0.000 & 0.000 & 0.000 \\
\hline & Trading Volume & 0 & 0.000 & 0.251 & 0.000 & 0.000 & 0.217 & 0.019 & 0.028 & 0.000 & 0.000 & 0.292 & 0.000 & 0.327 & 0.000 & 0.117 & 0.000 & 0.000 & 0.000 & 0.000 \\
\hline & Head and shoulders & 0 & 0.000 & 0.138 & 0.000 & 0.000 & 0.000 & $\mid 0.000$ & 0.000 & 0.000 & 0.000 & 0.000 & 0.000 & 0.000 & 0.000 & 0.000 & 0.000 & 0.000 & 0.000 & 0.000 \\
\hline & Symmetrical triangles & 0 & 0.000 & 0.120 & 0.000 & 0.000 & 0.000 & 0.000 & 0.000 & 0.000 & 0.000 & 0.000 & 0.000 & 0.000 & 0.000 & 0.000 & 0.000 & 0.000 & 0.000 & 0.000 \\
\hline & Psychological factors & 0 & 0.000 & 0.000 & 0.665 & 0.000 & 0.013 & 0.551 & 0.278 & 0.000 & 0.000 & 0.021 & 0.000 & 0.021 & 0.000 & 0.115 & 0.000 & 0.000 & 0.000 & 0.000 \\
\hline & Societal factors & 0 & 0.000 & 0.000 & 0.335 & 0.000 & 0.057 & 0.040 & 0.025 & 0.000 & 0.000 & \begin{tabular}{|l|}
0.078 \\
\end{tabular} & 0.000 & 0.086 & 0.000 & 0.444 & 0.000 & 0.000 & 0.270 & 0.000 \\
\hline
\end{tabular}

Figure 6. Supermatrix (after combining the results of both methods)

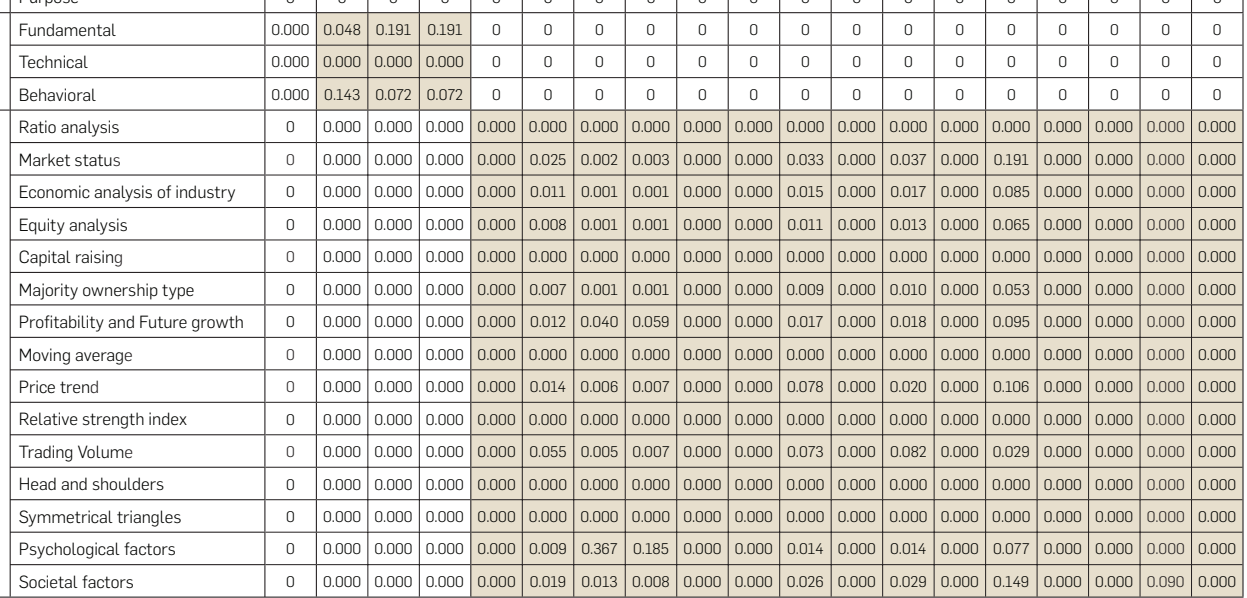


Figure 7. Weighted supermatrix

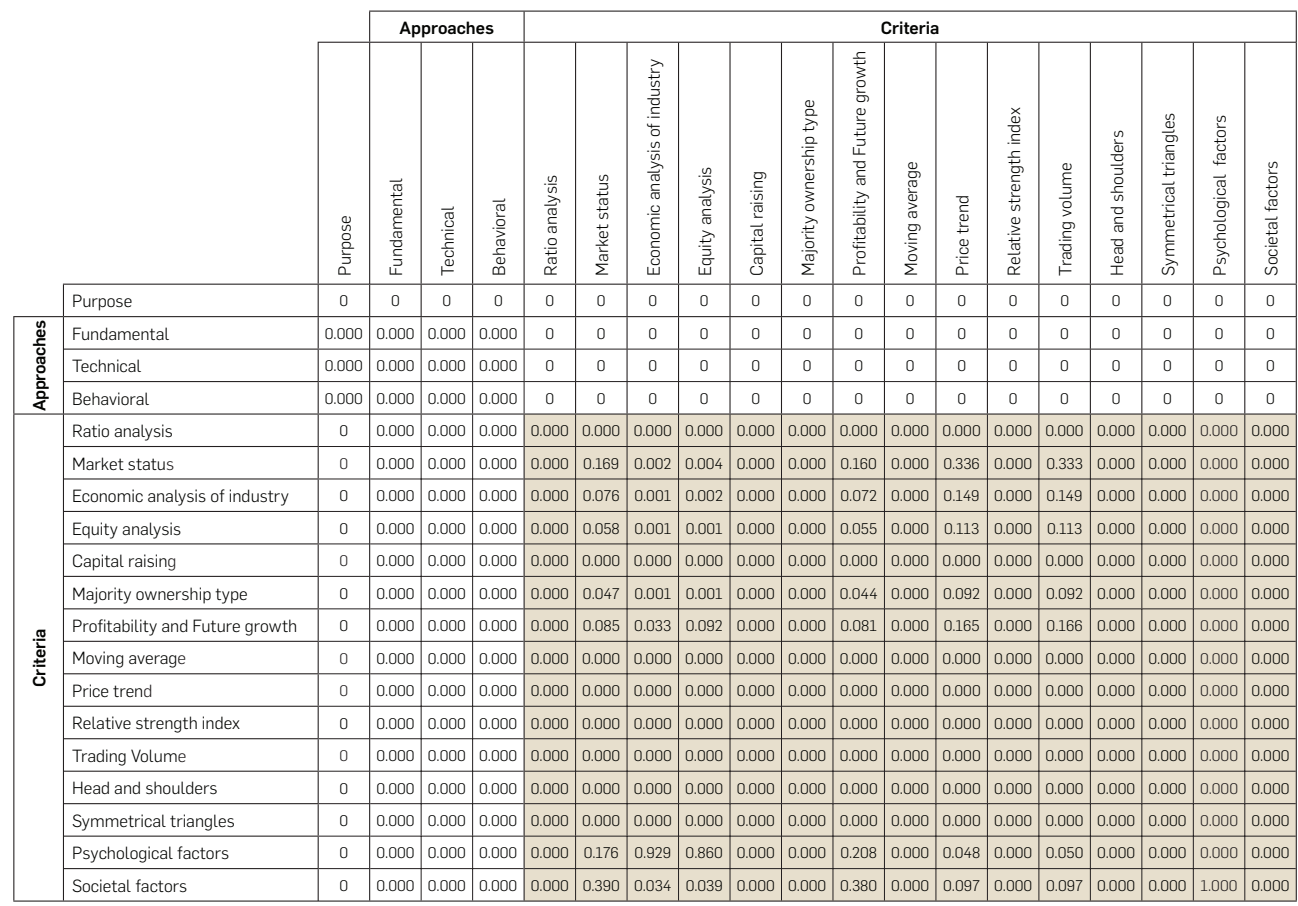

Table 6 . The weight priority of approaches and criteria

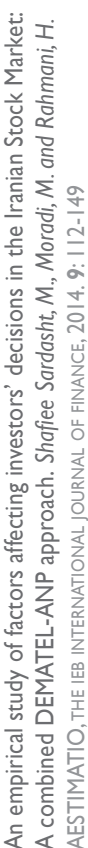

\begin{tabular}{lll}
\hline \multicolumn{1}{c}{ Criteria } & Weight & Ranking \\
\hline \multicolumn{1}{c}{ Fundamental analysis } & & 0.124 \\
\hline Ratio analysis & 0 & \\
\hline Market status & 0.045 & 3 \\
\hline Economic analysis of industry & 0.02 & 5 \\
\hline Equity analysis & 0.015 & 6 \\
\hline Capital raising & 0 & \\
\hline Majority ownership type & 0.013 & 7 \\
\hline Profitability and Future growth & 0.03 & 4 \\
\hline \multicolumn{1}{c}{ Behavioral factors } & & \\
\hline Psychological factors & 0.167 & \\
\hline Societal factors & 0.71 & \\
\hline \multicolumn{1}{c}{ Technical analysis } & & \\
\hline Moving average & 0 & \\
\hline Price trend & 0 & \\
\hline Relative strength index & 0 & \\
\hline Trading Volume & 0 & \\
\hline Head and shoulders & 0 & \\
\hline Symmetrical triangles & & \\
\hline
\end{tabular}


As shown in Table 6, the Behavioral factors approach had the highest weight (0.876) compared to Fundamental and Technical approaches. This indicates the high relative effect of Behavioral factors on Iranian investors' stock purchase decisions.

According to the obtained weights, research criteria can be divided into two major categories:

1. The first category contains the criteria affecting investors' decisions during stock, including Societal factors, among others. It has the highest weight and greatest effect (0.71) on investors' decisions (Table 6). This indicates that investors give more consideration to Societal factors when buying stock. Also, based on the weight priority for Societal factors (Table 7), it can be said that Political factors and Investors' recommendations have a weight of 0.335 and 0.248 , which are the highest weight among Societal factors as sub-criteria. The sub-criteria of Herd behavior, Rumors and Institutional investors are weighted at 0.184, 0.147 and 0.085 , respectively. Psychological factors $(0.167)$ are ranked second after Societal factors (Table 6). The sub-criteria of Past stock price, Risk-seeking and Overconfidence are weighted at $0.437,0.410$ and 0.153 , respectively (Table 7). Market status (0.045), Profitability and Future growth (0.030), Economic Analysis of Industry (0.020), Firm analysis (0.015) and Majority ownership type (0.013) are ranked after Psychological factors.

\section{Figure 7. The relative weight vector of Societal and psychological factors}

\begin{tabular}{|c|c|c|c|}
\hline \multicolumn{4}{|c|}{ Relative Weight Vector } \\
\hline & Sub-criteria & Weight & Ranking \\
\hline \multirow[t]{5}{*}{ Societal factors } & Political factors & 0.335 & 1 \\
\hline & Investors' recommendations & 0.248 & 2 \\
\hline & Herd behavior & 0.184 & 3 \\
\hline & Rumors & 0.147 & 4 \\
\hline & Institutional investors & 0.085 & 5 \\
\hline \multirow[t]{3}{*}{ Psychological factors } & Past stock price & 0.437 & 1 \\
\hline & Overconfidence & 0.153 & 3 \\
\hline & Risk-seeking & 0.41 & 2 \\
\hline
\end{tabular}

2. The second category includes the Technical approach, Ratio analysis and Capital raising criteria. These approaches and criteria have zero weight, which indicates that, relatively speaking, investors do not use these approaches and criteria for decision-making in when choosing stock. 


\section{Discussion and conclusion}

The empirical results show that Iranian investors tend to favor the Behavioral approach when choosing stock, and the most important criterion of this approach is Societal factors. That is to say, investors' decisions are principally driven by factors outside their decision-making character and non-financial-based analyses. They do not use complicated Technical analysis methods for stock purchase.

According to ANP, from the brokers' point of view, Political factors is the highest weighted of the Societal criteria, followed by other Investors' recommendations and then Herd behavior. This fact shows that Political factors have the greatest effect on investors' decisions when buying stock. On the other hand, investors less frequently use personal and scientific analysis for stock purchase. They select the stocks mostly based on other Investors' recommendations and Herd behavior, which happens at a specific time of stock purchase. Undoubtedly, identification of the factors affecting stock purchasers' decisions can lay the groundwork for providing them with good investment advice and limiting the influence of news and Rumors. Political factors affect Iranian investors' decisions more than other factors and consequently have a significant effect on stock price volatility and shareholders' interest in stock purchases. Furthermore, according to brokers, investors tend to be motivated by herd behavior. This suggests that investors and shareholders mostly act in line with the actions of a group rather than relying on their personal capabilities. They base decisions on feelings rather than on logical decisions and scientific methods. The reason for this could be due to investors' poor financial knowledge and a lack of confidence in their own individual capabilities. Therefore, it can be implicitly argued that Iranian individual investors act in strict accordance with the market environment and the behavior of large institutional investors when choosing stock.

In most cases, investors start purchasing or selling stock upon hearing news, without waiting for reliable analyzed information. This can explain the emergence in the TSE of "long queues" to urgently purchase stock, which results in high volatility in the market. The findings also point to the significant effect of Rumors on the choices of stock purchasers. There are several reasons for this; the most important is investors' inaccurate analysis of firms' stocks and their short-term investment view which naturally exacerbates the effect of Rumors on their behavior. It is supposed that many Rumors are more easily spread due to firms' failing to issue accurate and timely notifications. According to research results and based on other studies which focused on separate investment approaches in Iran, it can be argued that the combined approach is better able to identify the factors affecting investors' stock purchasing decisions. 
Abarbanell, J.S. and Bushee, B.J. (1998). Abnormal returns to a fundamental analysis strategy, The Accounting Review, 73 (1), pp. 19-45.

- Alexander, S.S. (1961). Price movements in speculative markets: trends or random walks, Industrial Management Review, 2, pp. 7-26.

Al-Tamimi, H.A.H. (2006). Factors influencing individual investor behavior: an empirical study of the UAE financial markets, The Business Review, 5(2), pp. 225-233.

Anderson, J.A. and Faff, R.W. (2008). Point and Figure charting: A computational methodology and trading rule performance in the S\&P 500 futures market, International Review of Financial Analysis, 17(1), pp. 198-217.

Armano, G., Marchesi, M. and Murru, A. (2005). A hybrid genetic-neural architecture for stock indexes forecasting, Information Sciences, 170(1), pp. 3-33.

Barber, B., Lehavy, R., McNichols, M. and Trueman, B. (2001). Can investors profit from the prophets? Security analyst recommendations and stock returns, The Journal of Finance, 56(2), pp. 531-563.

Beckwith, J. (2001). Stock Selection in Six Major Non-US Markets, The Journal of Investing, 10(2), pp. 37-44.

Biais, B., Hilton, D., Mazurier, K. and Pouget, S. (2002). Psychological traits and trading strategies, Discussion Paper Series No. 3195, Research Program in Financial Economics, Centre for Economic Policy Research, London. Available online at: www.cepr.org/pubs/dps/DP3195.asp $\square$

Blume, M. and Friend, I. (1978). The changing role of the individual investor, Wiley, New York.

Blume, L., Easley, D. and O'hara, M. (1994). Market statistics and technical analysis: The role of volume, The Journal of Finance, 49(1), pp. 153-181.

Brabazon, T. (2000). Behavioral Finance: A new sunrise or a false dawn, Coil Summer School, University of Limerick, 28th August-3rd September 2000.

Brav, A., Geczy, C. and Gompers, P.A. (2000). Is the abnormal return following equity issuances anomalous?, Journal of Financial Economics, 56(2), pp. 209-249.

Brock, W., Lakonishok, J. and LeBaron, B. (1992). Simple technical trading rules and the stochastic properties of stock returns, The Journal of Finance, 47(5), pp. 1731-1764.

Büyüközkan, G. and Çifçi, G. (2012). A novel hybrid MCDM approach based on fuzzy DEMATEL, fuzzy ANP and fuzzy TOPSIS to evaluate green suppliers, Expert Systems with Applications, 39(3), pp. 3000-3011.

Campbell, J. and Sheller R. (1988). Stock prices, earnings and expected dividends, Journal of Finance, 43(3), pp. 661-76.

Campbell, J. (1987). Stock returns and term structure, Journal of Financial Economics, 18(2), pp. 373-399.

Caparrelli, F., D'Arcangelis, A.M. and Cassuto, A. (2004). Herding in the Italian stock market: a case of behavioral finance, The Journal of Behavioral Finance, 5(4), pp. 222-230.

Chang, E.C., Cheng, J.W. and Khorana, A. (2000). An examination of herd behavior in equity markets: An international perspective, Journal of Banking \& Finance, 24(10), pp. 1651-1679.

Chen, C.A., (2012). Using DEMATEL Method for Medical Tourism Development in Taiwan, American Journal of Tourism Research, 1(1), pp. 26-32. 
Cheng, P.Y. (2007). The trader interaction effect on the impact of overconfidence on trading performance: An empirical study, The Journal of Behavioral Finance, 8(2), pp. 59-69.

Cheng, E.W.L. and Li, H. (2007). Application of ANP in process models: An example of strategic partnering, Building and Environment, 42(1), pp. 278-287.

Clubb, N. and Naffi, M. (2007). The usefulness of book-to-market and ROE expectations for explaining UK stock returns, Journal of Business Finance and Accounting, 34(1/2), pp. 1-32.

Cochrane, J.H. (1991). Production-based asset pricing and the link between stock returns and economic fluctuations, Journal of Finance, 46(1), pp. 209-38.

Cole, R.A., Moshirian, F. and Wu, Q. (2008). Bank stock returns and economic growth, Journal of Banking \& Finance, 32(6), pp. 995-1007.

Cunningham, S. (1973). The predictability of British stock market prices, Applied Statistics, 22, pp. 315-231.

Daniel, K., Hirshleifer, D. and Subrahmanyam, A. (1998). Investor psychology and security market under-and overreactions, The Journal of Finance, 53(6), pp. 1839-1885.

Dann, L.Y., Mayers, D. and Raab, R.J. (1977). Trading rules, large blacks and the speed of price adjustment, Journal of Financial Economics, 4, pp. 3-22.

Dryden, M., (1970). Filter tests of UK share prices, Applied Economics, 1(4), pp. 261-275.

Edirisinghe, N.C.P. and Zhang, X. (2007a). Generalized DEA model of fundamental analysis and its application to portfolio optimization, Journal of Banking \& Finance, 31(11), pp. 3311-3335.

Edirisinghe, N.C.P. and Zhang, X. (2007b). Portfolio selection under DEA-based relative financial strength indicators: case of US industries, Journal of the Operational Research Society, 59(6), pp. 842-856.

Edwards, R.D., Magee, J. and Bassetti, W.H.C. (2012). Technical analysis of stock trends, CRC Press, Boca Raton.

Ellis, C.A. and Parbery, S.A. (2005). Is smarter better? A comparison of adaptive and simple moving average trading strategies, Research in International Business and Finance, 19(3), pp. 399-411.

Fama, E.F. and French, K. (1989). Business conditions and expected returns on stocks and bonds, Journal of Financial Economics, 25(1), pp. 23-49.

Fama, E.F. and French, K.R. (2006). Profitability, investment and average returns, Journal of Financial Economics, 82(3), pp. 491-518.

Fama, E.F. and Blume, M. (1966). Filter rules and stock market trading profits, Journal of Business, 39(1), pp. 226-241.

Fuller, R.J. (1998). Behavioral finance and the sources of alpha, Journal of Pension Plan Investing, 2(3), pp. 291-293.

Gencer, C. and Gürpinar, D. (2007). Analytic network process in supplier selection: A case study in an electronic firm, Applied Mathematical Modelling, 31(11), pp. 2475-2486.

Girard, E. and Omran, M. (2007). What are the risks when investing in thin emerging equity markets: Evidence from the Arab world, Journal of International Financial Markets, Institutions and Money, 17(1), pp. 102-123.

Glaser, M. and Weber, M. (2007). Overconfidence and trading volume, The Geneva Risk and Insurance Review, 32(1), pp. 1-36.

Groenewold, N., Kan Tang, S.H. and Wu, Y. (2008). The profitability of regression-based trading rules for the Shanghai stock market, International Review of Financial Analysis, 17(2), pp. 411-430. 
Gunasekarage, A. and Power, D.M. (2001). The profitability of moving average trading rules in South Asian stock markets, Emerging Markets Review, 2(1), pp. 17-33.

Hartono, J., (2004). The recency effect of accounting information, Gadjah Mada International Journal of Business, 6(1), pp. 85-116.

Hirose, T., Kato, H.K. and Bremer, M. (2009). Can margin traders predict future stock returns in Japan?, PacificBasin Finance Journal, 17(1), pp. 41-57.

Huddart, S., Lang, M. and Yetman, M. (2003). Psychological factors, stock price paths, and trading volume, Working Paper, Pennsylvania State University.

Hudson, R., Dempsey, M. and Keasey, K. (1996). A note on the weak form efficiency of capital markets: The application of simple technical trading rules to UK stock prices-1935 to 1994, Journal of Banking \& Finance, 20(6), pp. 1121-1132.

Hoffmann, A.O. and Fischer, E.T.S. (2012). Behavioral Aspects of Covered Call Writing: An Empirical Investigation, Journal of Behavioral Finance, 13(1), pp. 66-79.

Hunton, J.E., McEwen, R.A. and Bhattacharjee, S. (2001). Toward an understanding of the risky choice behavior of professional financial analysts, The Journal of Psychology and Financial Markets, 2(4), pp. 182-189.

Kalev, P.S., Liu, W.M., Pham, P.K. and Jarnecic, E. (2004). Public information arrival and volatility of intraday stock returns, Journal of Banking \& Finance, 28(6), pp. 1441-1467.

Kim, K.A. and Nofsinger, J.R. (2007). The behavior of Japanese individual investors during bull and bear markets, The Journal of Behavioral Finance, 8(3), pp. 138-153.

Kho, B.C. (1996). Time-varying risk premia, volatility, and technical trading rule profits: Evidence from foreign currency futures markets, Journal of Financial Economics, 41(2), pp. 249-290.

Kothari, S.P., Lewellen, J. and Warner, J.B. (2006). Stock returns, aggregate earnings surprises, and behavioral finance, Journal of Financial Economics, 79(3), pp. 537-568.

Lee, W.S., Huang, A.Y., Chang, Y.Y. and Cheng, C.M. (2011). Analysis of decision making factors for equity investment by DEMATEL and Analytic Network Process, Expert Systems with Applications, 38(7), pp. 8375-838.

Letamendia, L.N. (2007). Fitting the control parameters of a genetic algorithm: An application to technical trading systems design, European Journal of Operational Research, 179(3), pp. 847-868.

Levich, R.M. and Thomas III, L.R. (1993). The significance of technical trading-rule profits in the foreign exchange market: a bootstrap approach, Journal of International Money and Finance, 12(5), pp. 451-474.

Lin, C.J. and Wu, W.W. (2008). A Causal Analytical Method for Group Decision-Making under Fuzzy Environment, Expert Systems with Applications, 34(1), pp. 205-213.

Li, C.W. and Tzeng, G.H., (2009). Identification of a threshold value for the DEMATEL method using the maximum mean de-entropy algorithm to find critical services provided by a semiconductor intellectual property mall, Expert Systems with Applications, 36(6), pp. 9891-9898.

Liu, J.N. and Kwong, R.W., (2007). Automatic extraction and identification of chart patterns towards financial forecast, Applied Soft Computing, 7(4), pp. 1197-1208.

Lo, A.W., Mamaysky, H. and Wang, J. (2000). Foundations of technical analysis: Computational algorithms, statistical inference, and empirical implementation, The Journal of Finance, 55(4), pp. 1705-1770.

Lu, B., Song, X.Y. and Li, X.D. (2012). Bayesian analysis of multi-group nonlinear structural equation models with application to behavioral finance, Quantitative Finance, 12(3), pp. 477-488. 
- Marshall, B.R. and Cahan, R.H. (2005). Is technical analysis profitable on a stock market which has characteristics that suggest it may be inefficient?, Research in International Business and Finance , 19(3), pp. 384-398.

Ming-Ming, L. and Siok-Hwa, L. (2006). The profitability of the simple moving averages and trading range breakout in the Asian stock markets, Journal of Asian Economics, 17(1), pp. 144-170.

Mishkin, F.S. (2004). Can inflation targeting work in emerging market countries?, National Bureau of Economic Research, NBER Working Paper, No.W10646, July.

Mizuno, H., Kosaka, M. and Yajima, H. (1998). Application of neural network to technical analysis of stock market prediction, Studies in Informatics and Control, 7(2), pp. 111-120.

Nguyen, H. and Chen, H. (2008). Institutional Herding and its impact on stock prices, Financial Management Association Meeting, University of Florida \& Baltimore.

Oberlechner, T. (2001). Importance of technical and fundamental analysis in the European foreign exchange market, International Journal of Finance \& Economics, 6(1), pp. 81-93.

Osler, C. and Chang, P.H. (1995). Head and shoulders: Not just a flaky pattern, Staff Reports, 4, Federal Reserve Bank of New York.

Ou Yang, Y.P., Shieh, H.M., Leu, J.D. and Tzeng, G.H. (2008). A novel hybrid MCDM model combined with DEMATEL and ANP with applications, International Journal of Operations Research, 5(3), pp. 160-168.

- Pompian, M.M. (2006). Behavioral finance and wealth management, John Wiley \& Sons Inc, New Jersey.

Quirin, J.J., Berry, K.T. and O'Brien, D. (2000). A fundamental analysis approach to oil and gas firm valuation, Journal of Business Finance \& Accounting, 27(7-8), pp. 785-820.

Renshaw, E. (1993). Modeling the stock market for forecasting purposes, Journal of Portfolio Management, 20(1), pp. $76-81$.

Ritter, J.R., (2003). Behavioral finance, Pacific-Basin Finance Journal, 11(4), pp. 429-437.

Rosillo, R., De la Fuente, D. and Brugos, J.A.L. (2013). Technical analysis and the Spanish stock exchange: testing the RSI, MACD, momentum and stochastic rules using Spanish market companies, Applied Economics, 45(12), pp. 1541-1550.

Rozeff, M.S. (1974). Money and stock prices, market efficiency and the lag in effect of monetary policy, Journal of Financial Economics, 1(3), pp. 245-302.

Saaty, T.L. (1996). Decision making with dependence and feedback: The analytic network process, RWS Publications, Pittsburgh.

Saaty, T.L. (2004). Fundamentals of the analytic network process-multiple networks with benefits, costs, opportunities and risks, Journal of Systems Science and Systems Engineering, 13(3), pp. 348-379.

Saaty, T.L. (2005). Theory and applications of the analytic network process: decision making with benefits, opportunities, costs, and risks, RWS publications, Pittsburgh.

Savin, G., Weller, P. and Zvingelis, J. (2007). The predictive power of "head-and-shoulders" price patterns in the US stock market, Journal of Financial Econometrics, 5(2), pp. 243-265.

Sevkli, M., Koh, S. L., Zaim, S., Demirbag, M. and Tatoglu, E. (2008). Hybrid analytical hierarchy process model for supplier selection, Industrial Management \& Data Systems, 108(1), pp. 122-142. 
Samaras, G.D., Matsatsinis, N.F. and Zopounidis, C. (2008). A multicriteria DSS for stock evaluation using fundamental analysis, European Journal of Operational Research, 187(3), pp. 1380-1401.

Shapira, Z. and Venezia, I. (2001). Patterns of behavior of professionally managed and independent investors, Journal of Banking \& Finance, 25(8), pp. 1573-1587.

Flynn, S. (2008). Behavioral Finance, Research Starters Business, Magazine article, pp. 1-13.

Squyres, J.G., (1998). A Quick Peek According to Graham and Dodd, Journal of Financial Statement Analysis, 4, pp. 79-83.

Tanaka-Yamawaki, M. and Tokuoka, S. (2007). Adaptive use of technical indicators for the prediction of intra-day stock prices, Physica A: Statistical Mechanics and its Applications, 383(1), pp. 125-133.

Tan, L., Chiang, T.C., Mason, J.R. and Nelling, E. (2008). Herding behavior in Chinese stock markets: An examination of $A$ and B shares, Pacific-Basin Finance Journal, 16(1), pp. 61-77.

Tang, G.Y. and Shum, W.C. (2003). The conditional relationship between beta and returns: recent evidence from international stock markets, International Business Review, 12(1), pp. 109-126.

Thaler, R.H. (1999). The end of behavioral finance, Financial Analysts Journal, 55(6), pp. 12-17.

Trevithick, S., Flabouris, A., Tall, G. and Webber, C. (2003). International EMS systems: New South Wales, Australia, Resuscitation, 59(2), pp. 165-70.

Tsai, W.H. and Chou, W.C. (2009). Selecting management systems for sustainable development in SMEs: A novel hybrid model based on DEMATEL, ANP, and ZOGP, Expert Systems with Applications, 36(2), pp. 1444-1458.

Tzeng, G.H., Chen, W.H., Yu, R. and Shih, M.L. (2010). Fuzzy decision maps: a generalization of the DEMATEL methods, Soft Computing, 14(11), pp. 1141-1150.

Wang, J. L. and Chan, S.H. (2006). Stock market trading rule discovery using two-layer bias decision tree, Expert Systems with Applications, 30(4), pp. 605-611.

Wang, L., Chu, J. and Wu, J., (2007). Selection of optimum maintenance strategies based on a fuzzy analytic hierarchy process, International Journal of Production Economics, 107(1), pp. 151-163.

Wang, L. and Tzeng, G.H. (2012). Brand marketing for creating brand value based on a MCDM model combining DEMATEL with ANP and VIKOR methods, Expert Systems with Applications, 39(5), pp. 5600-5615.

Wisniewski, T. P. (2009). Can political factors explain the behaviour of stock prices beyond the standard present value models?, Applied Financial Economics, 19(23), pp. 1873-1884.

Wong, W.K., Manzur, M. and Chew, B.K., (2003). How rewarding is technical analysis? Evidence from Singapore stock market, Applied Financial Economics, 13(7), pp. 543-551.

Wu, W.W. and Xu, J.P. (2006). Fundamental analysis of stock price by artificial neural networks model based on rough set theory, World Journal of Modelling and Simulation, 1(2), pp. 36-44.

Wu, W.W. and Lee, Y.T. (2007). Developing global managers' competencies using the fuzzy DEMATEL method, Expert Systems with Applications, 32(2), pp. 499-507.

Wu, W.W. (2008). Choosing knowledge management strategies by using a combined ANP and DEMATEL approach, Expert Systems with Applications, 35(3), pp. 828-835. 
Wurgler, J., Bradley, B. and Baker, M., (2010). A Behavioral Finance Explanation for the Success of Low Volatility Portfolios. Available at: https://www.archive.nyu.edu/handle/2451/29537 $\square$

Xu, J. and Wu, W.W. (2006). Multiple attribute decision making theory and methods. Tsinghua University Press, Beijing.

Yang, J.L. and Tzeng, G.H. (2011). An integrated MCDM technique combined with DEMATEL for a novel clusterweighted with ANP method, Expert Systems with Applications, 38(3), pp. 1417-1424.

Yildiz, B. and Yezegel, A. (2010). Fundamental analysis with artificial neural network, International Journal of Business \& Finance Research, 4(1), pp. 149-158.

Zarandi, M.H.F., Rezaee, B., Turksen, I.B. and Neshat, E. (2009). A type-2 fuzzy rule based expert system model for stock price analysis, Expert Systems with Applications, 36(1), pp. 139-154.

\section{Appendix A.The questionnaire}

Dear Expert,

This questionnaire was designed in order to conduct a scientific study regarding the prioritization of factors affecting the decision of investors in the Tehran Stock Exchange (TSE). Due to the limited population of this study in terms of the plurality of experts, please answer the questions with full care and patience. Your opinions will certainly contribute to the quality of this research. We remind that your responses are completely confidential and will be used only for scientific analysis. Also, if you are interested in the research results, a summary of the findings will be sent to you. Thank you in advance for your cooperation.

The questionnaire is divided into the following sections:

Section I: General information.

Section II: Pairwise comparisons to determine the degree of preference.

Section III: Pairwise comparisons to determine the degree of influencing and being influenced.

\section{Section I: General information}

\begin{tabular}{ll}
\hline Age: & Experience: \\
\hline Sex: & Organizational position: \\
\hline Education: & E-mail: \\
\hline Field of Study: & Phone Number: \\
\hline
\end{tabular}




\section{Section II: Pairwise comparisons to determine the degree of preference}

This section consists of pairwise comparisons to determine the degree of preference for approaches, criteria and sub-criteria, with respect to each other. Please answer the questions in this section according to the information in the Help Table.

\begin{tabular}{cl}
\hline Numeral & Definition \\
\hline $\begin{array}{l}2 \\
2\end{array}$ & Equal importance \\
\hline 3 & Intermediate value between 1 and 3 \\
\hline 4 & Intermediate value between 3 and 5 \\
\hline 5 & Strong or essential importance \\
\hline 6 & Intermediate value between 5 and 7 \\
\hline 7 & Very strong or demonstrated importance \\
\hline 9 & Intermediate value between 7 and 9 \\
\hline
\end{tabular}

Note: When comparing two factors in pairwise comparisons, if you prefer the right option (Factor A), mark one of the numbers 1 to 9 on the right side of the table. If you prefer the left option (Factor B), mark one of the numbers 1 to 9 on the left side of the table, given the importance level guidance. If the relative importance of the two factors is equal, mark the same option (equivalent to number 1 ) which is located in the middle of the two series of numbers.

\begin{tabular}{|l|l|l|l|l|l|l|l|l|l|l|l|l|l|l|l|l|l|l|}
\hline B & 9 & 8 & 7 & 6 & 5 & 4 & 3 & 2 & 1 & 2 & 3 & 4 & 5 & 6 & 7 & 8 & 9 & A \\
\hline
\end{tabular}

1) According to the research objective, which of the following approaches is more important?

\begin{tabular}{l|l|l|l|l|l|l|l|l|l|l|l|l|l|l|l|l|l|l} 
Approach & 9 & 8 & 7 & 6 & 5 & 4 & 3 & 2 & 1 & 2 & 3 & 4 & 5 & 6 & 7 & 8 & 9 & Approach \\
\hline Technical & & & & & & & & & & & & & & & & & & Fundamental \\
\hline Behavioral & & & & & & & & & & & & & & & & & & Fundamental \\
\hline Behavioral & & & & & & & & & & & & & & & & & & Technical \\
\hline
\end{tabular}


2) According to the research objective, state the degree of importance of each of the following criteria in the Fundamental Analysis approach.

\begin{tabular}{|c|c|c|c|c|c|c|c|c|c|c|c|c|c|c|}
\hline Criteria & 9 & 87 & 76 & 5 & 4 & 32 & \begin{tabular}{l|l}
2 & 1
\end{tabular} & 12 & 34 & 45 & 67 & 78 & 9 & Criteria \\
\hline Market status & & & & & & & & & & & & & & Ratio analysis \\
\hline Economic Analysis of Industry & & & & & & & & & & & & & & Ratio analysis \\
\hline Equity analysis & & & & & & & & & & & & & & Ratio analysis \\
\hline Profitability and Future growth & & & & & & & & & & & & & & Ratio analysis \\
\hline Capital raising & & & & & & & & & & & & & & Ratio analysis \\
\hline Majority ownership type & & & & & & & & & & & & & & Ratio analysis \\
\hline Economic Analysis of Industry & & & & & & & & & & & & & & Market status \\
\hline Equity analysis & & & & & & & & & & & & & & Market status \\
\hline Profitability and Future growth & & & & & & & & & & & & & & Market status \\
\hline Capital raising & & & & & & & & & & & & & & Market status \\
\hline Majority ownership type & & & & & & & & & & & & & & Market status \\
\hline Equity analysis & & & & & & & & & & & & & & Economic Analysis of Industry \\
\hline Profitability and Future growth & & & & & & & & & & & & & & Economic Analysis of Industry \\
\hline Capital raising & & & & & & & & & & & & & & Economic Analysis of Industry \\
\hline Majority ownership type & & & & & & & & & & & & & & Economic Analysis of Industry \\
\hline Profitability and Future growth & & & & & & & & & & & & & & Equity analysis \\
\hline Capital raising & & & & & & & & & & & & & & Equity analysis \\
\hline Majority ownership type & & & & & & & & & & & & & & Equity analysis \\
\hline Capital raising & & & & & & & & & & & & & & Profitability and Future growth \\
\hline Majority ownership type & & & & & & & & & & & & & & Profitability and Future growth \\
\hline Majority ownership type & & & & & & & & & & & & & & Capital raising \\
\hline
\end{tabular}

3) According to the research objective, state the degree of importance of each of the following criteria in the Technical Analysis approach.

\begin{tabular}{|c|c|c|c|c|c|c|c|c|c|c|c|c|c|c|c|c|}
\hline Criteria & 9 & 8 & $7 \mid t$ & $6 \mid t$ & $\left.5\right|^{2}$ & $4 \mid:$ & 2 & 1 & 2 & 3 & 4 & $5 \mid$ & $6 \mid 7$ & $7 \mid 8$ & 9 & Criteria \\
\hline Price trend & & & & & & & & & & & & & & & & Moving average \\
\hline Relative strength index & & & & & & & & & & & & & & & & Moving average \\
\hline Trading volume & & & & & & & & & & & & & & & & Moving average \\
\hline Head and shoulders & & & & & & & & & & & & & & & & Moving average \\
\hline Symmetrical triangles & & & & & & & & & & & & & & & & Moving average \\
\hline Relative strength index & & & & & & & & & & & & & & & & Price trend \\
\hline Trading volume & & & & & & & & & & & & & & & & Price trend \\
\hline Head and shoulders & & & & & & & & & & & & & & & & Price trend \\
\hline Symmetrical triangles & & & & & & & & & & & & & & & & Price trend \\
\hline Trading volume & & & & & & & & & & & & & & & & Relative strength index \\
\hline Head and shoulders & & & & & & & & & & & & & & & & Relative strength index \\
\hline Symmetrical triangles & & & & & & & & & & & & & & & & Relative strength index \\
\hline Head and shoulders & & & & & & & & & & & & & & & & Trading volume \\
\hline Symmetrical triangles & & & & & & & & & & & & & & & & Trading volume \\
\hline Symmetrical triangles & & & & & & & & & & & & & & & & Head and shoulders \\
\hline
\end{tabular}


4) According to the research objective, state the degree of importance of each of the following criteria in the Behavioral Finance approach.

5) According to the research objective, state the degree of importance of each of the following sub-criteria in the Financial ratio analysis criterion.

\begin{tabular}{|c|c|c|c|c|c|c|c|c|c|c|c|c|c|c|c|}
\hline Sub-criteria & 9 & 8 & 7 & 6 & 5 & $4 \mid 3$ & \begin{tabular}{l|l}
3 & 2
\end{tabular} & 1 & \begin{tabular}{l|l}
2 & 3
\end{tabular} & 4 & 56 & \begin{tabular}{l|l|}
6 & 7
\end{tabular} & 8 & 9 & Sub-criteria \\
\hline EPS & & & & & & & & & & & & & & & DPS \\
\hline$P / E$ & & & & & & & & & & & & & & & DPS \\
\hline ROE & & & & & & & & & & & & & & & DPS \\
\hline MV/BV & & & & & & & & & & & & & & & DPS \\
\hline$P / E$ & & & & & & & & & & & & & & & EPS \\
\hline ROE & & & & & & & & & & & & & & & EPS \\
\hline MV/BV & & & & & & & & & & & & & & & EPS \\
\hline $\mathrm{ROE}$ & & & & & & & & & & & & & & & $\mathrm{P} / \mathrm{E}$ \\
\hline MV/BV & & & & & & & & & & & & & & & $P / E$ \\
\hline MV/BV & & & & & & & & & & & & & & & ROE \\
\hline
\end{tabular}

6) According to the research objective, state the degree of importance of each of the following sub-criteria in the Moving average criterion.

\begin{tabular}{l|l|l|l|l|l|l|l|l|l|l|l|l|l|l|l|l|l|l} 
Sub-criteria & 9 & $\mathbf{8}$ & $\mathbf{7}$ & $\mathbf{6}$ & $\mathbf{5}$ & $\mathbf{4}$ & $\mathbf{3}$ & $\mathbf{2}$ & $\mathbf{1}$ & $\mathbf{2}$ & $\mathbf{3}$ & $\mathbf{4}$ & $\mathbf{5}$ & $\mathbf{6}$ & $\mathbf{7}$ & $\mathbf{8}$ & $\mathbf{9}$ & Sub-criteria \\
WMA & & & & & & & & & & & & & & & & & SMA \\
\hline EMA & & & & & & & & & & & & & & & & & SMA \\
\hline VMA & & & & & & & & & & & & & & & & SMA \\
\hline TMA & & & & & & & & & & & & & & & & SMA \\
\hline EMA & & & & & & & & & & & & & & & & WMA \\
\hline VMA & & & & & & & & & & & & & & & \\
\hline TMA & & & & & & & & & & & & & & & & WMA \\
\hline VMA & & & & & & & & & & & & & & & & & WMA \\
\hline TMA & & & & & & & & & & & & & & EMA \\
\hline TMA & & & & & & & & & & & & & & EMA \\
\hline
\end{tabular}

7) According to the research objective, state the degree of importance of each of the following sub-criteria in the Psychological factors criterion.

\begin{tabular}{l|l|l|l|l|l|l|l|l|l|l|l|l|l|l|l|l|l|l} 
Sub-criteria & 9 & $\mathbf{8}$ & $\mathbf{7}$ & $\mathbf{6}$ & $\mathbf{5}$ & $\mathbf{4}$ & $\mathbf{3}$ & $\mathbf{2}$ & $\mathbf{1}$ & $\mathbf{2}$ & $\mathbf{3}$ & $\mathbf{4}$ & $\mathbf{5}$ & $\mathbf{6}$ & $\mathbf{7}$ & $\mathbf{8}$ & $\mathbf{9}$ & Sub-criteria \\
\hline Past stock price & & & & & & & & & & & & & & & & & & Overconfidence \\
\hline Risk-seeking & & & & & & & & & & & & & & & & & Overconfidence \\
\hline Risk-seeking & & & & & & & & & & & & & & & \\
\hline
\end{tabular}


8) According to the research objective, state the degree of importance of each of the following sub-criteria in the Societal factors criterion.

\begin{tabular}{l|l|l|l|l|l|l|l|l|l|l|l|l|l|l|l|l|l|l}
\hline Sub-criteria & 9 & $\mathbf{8}$ & $\mathbf{7}$ & $\mathbf{6}$ & $\mathbf{5}$ & $\mathbf{4}$ & $\mathbf{3}$ & $\mathbf{2}$ & $\mathbf{1}$ & $\mathbf{2}$ & $\mathbf{3}$ & $\mathbf{4}$ & $\mathbf{5}$ & $\mathbf{6}$ & $\mathbf{7}$ & $\mathbf{8}$ & $\mathbf{9}$ & Sub-criteria \\
\hline Rumors & & & & & & & & & & & & & & & & Institutional investors \\
\hline Herd behavior & & & & & & & & & & & & & & & & Institutional investors \\
\hline Political factors & & & & & & & & & & & & & & & Institutional investors \\
\hline Investors' recommendations & & & & & & & & & & & & & & Institutional investors \\
\hline Herd behavior & & & & & & & & & & & & & & Rumors \\
\hline Political factors & & & & & & & & & & & & & & Rumors \\
\hline Investors' recommendations & & & & & & & & & & & & & & Rumors \\
\hline Political factors & & & & & & & & & & & & & & Herd behavior \\
\hline Investors' recommendations & & & & & & & & & & & & & & Herd behavior \\
\hline Investors' recommendations & & & & & & & & & & & & & Political factors \\
\hline
\end{tabular}

Section III: Pairwise comparisons to determine the degree of influencing and being influenced

This section presents pairwise comparisons for determining the scale of influencing and being influenced (identification of causal-effect relationships) among approaches, criteria and sub-criteria. By making pairwise comparisons between approaches and factors in each row, and between single elements and approach in each column, the scale of influence of each approach or factor on other approaches or factors is determined according to the overall rating criteria specified in the following table.

\begin{tabular}{cl}
\hline Numeral & Definition \\
\hline 0 & No influence \\
\hline 1 & Low influence \\
\hline 2 & Medium influence \\
\hline 3 & High influence \\
\hline 4 & Very high influence \\
\hline
\end{tabular}

Note 1: In answering the questionnaire, note that you should only assign scores to the direct relationship of the elements in row $A$ against the elements in column B. Do not consider the inverse relationship as it will also be addressed in the questionnaire. For example, if Criterion B affects Criterion A's performance, insert 2 in the related box.

Note 2: Ignore the indirect impact of A's row factor on B's column factor through other factors. 
1) State the degree of influence of Approaches on each other in order to prioritize factors affecting the investor's decision in the following pairwise comparisons.

\begin{tabular}{l|l|l|l|}
\cline { 2 - 4 } Approach & Fundamental & Technical & Behavioral \\
\hline Fundamental & & & \\
\hline Technical & & & \\
\hline Behavioral & & & \\
\hline
\end{tabular}

2) State the degree of influence of Criteria on each other in order to prioritize factors affecting the investor's decision in the following pairwise comparisons.

\begin{tabular}{|c|c|c|c|c|c|c|c|c|c|c|c|c|c|c|c|}
\hline Criteria & 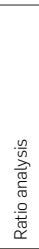 & 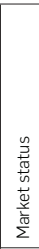 & 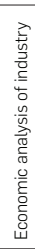 & 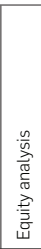 & 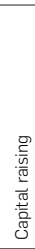 & 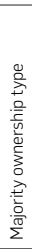 & 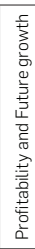 & 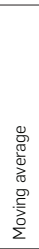 & 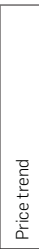 & 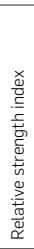 & 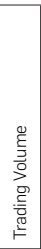 & 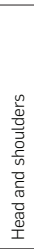 & 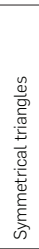 & 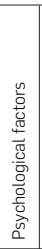 & 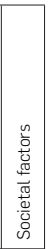 \\
\hline \multicolumn{16}{|l|}{ Ratio analysis } \\
\hline \multicolumn{16}{|l|}{ Market status } \\
\hline \multicolumn{16}{|c|}{ Economic analysis of industry } \\
\hline \multicolumn{16}{|l|}{ Equity analysis } \\
\hline \multicolumn{16}{|l|}{ Capital raising } \\
\hline \multirow{2}{*}{\multicolumn{16}{|c|}{\begin{tabular}{|l|} 
Majority ownership type \\
Profitability and Future growth \\
\end{tabular}}} \\
\hline & & & & & & & & & & & & & & & \\
\hline \multirow{2}{*}{\multicolumn{16}{|c|}{$\begin{array}{l}\text { Moving average } \\
\text { Price trend }\end{array}$}} \\
\hline & & & & & & & & & & & & & & & \\
\hline \multicolumn{16}{|l|}{ Relative strength index } \\
\hline \multicolumn{16}{|l|}{ Trading Volume } \\
\hline \multicolumn{16}{|l|}{ Head and shoulders } \\
\hline \multirow{2}{*}{\multicolumn{16}{|c|}{$\begin{array}{l}\text { Symmetrical triangles } \\
\text { Psychological factors }\end{array}$}} \\
\hline & & & & & & & & & & & & & & & \\
\hline Societal factors & & & & & & & & & & & & & & & \\
\hline
\end{tabular}

3) State the degree of influence of Sub-criteria on each other in order to prioritize factors affecting the investor's decision in the following pairwise comparisons.

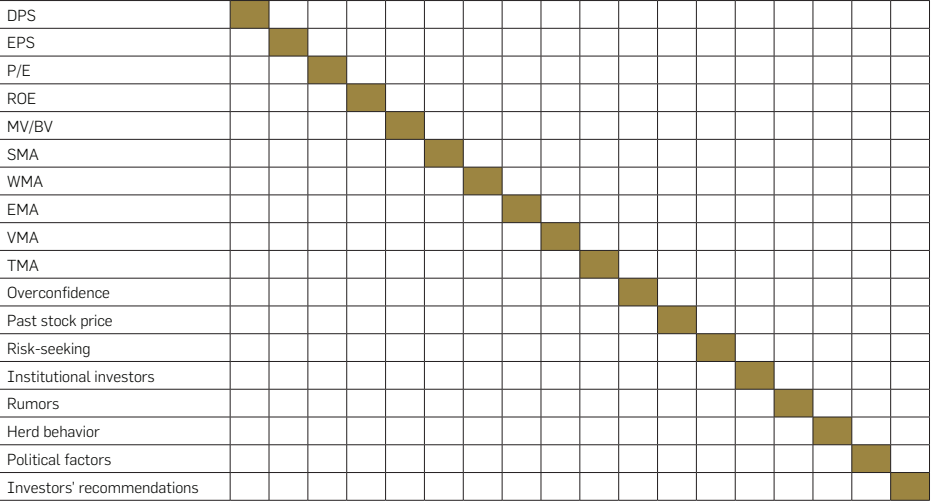




\section{Appendix B. Overview of AHP and ANP}

The AHP methodology, which was developed by Saaty (1980), helps analysts to organize the critical aspects of a problem into a hierarchical structure similar to a family tree (Sevkli et al., 2008).

In this process, a complex situation breaks down into smaller parts. Then these components are placed in a hierarchical structure. This method assigns numerical values to subjective judgments based on the importance of each variable and determines the most important variables. In other words, the priorities of variables are assigned. By ordering the group thinking process, the AHP method provides an effective structure for group decision-making. Moreover, the consensus nature in group decision-making improves the consistency of judgments, increasing the reliability of the AHP as a decision-making tool. Thus, with this method, one can understand problems that encompass several factors.

The basic assumption of this technique is that relationships between decision levels are unidirectional and hierarchical. It means that each decision level (the relationship between two nodes) only depends on the upper level (Gencer and Gürpinar, 2007). However, many multi-criteria decision problems cannot be considered in terms of a hierarchical structure due to inner and outer dependency, the relationships and also interactions between clusters of elements in decision levels. Thus, AHP ignores the relationship between criteria in the problem under consideration. Therefore, this kind of top-down linear structure is not applicable in very complex systems (Chung et al., 2005). However, by replacing hierarchy with network, the ANP technique does not impose a hierarchical structure on the problem and models the problem using a feedback system approach. In the Feedback System model, clusters link one by one in turn as a network system (Wu, 2008). With a comprehensive framework, the ANP technique can consider all the interactions and relationships between decision levels, forming a network structure (Saaty, 2004). The structural difference between hierarchy and network is depicted in Figure B1.

In the Figure, clusters represent decision levels and straight lines or arcs show the interactions between decision levels. The direction of arcs represents dependency, and loops represent the interdependency of elements in each cluster. The network relationship of the ANP method does not only present the relationship between rules, but also calculates the relative weightings of each rule. The results of these computations form a supermatrix (Tsai and Chou, 2009). 
Figure B1. Difference between a hierarchy and a network: (a) a hierarchy; (b) a network

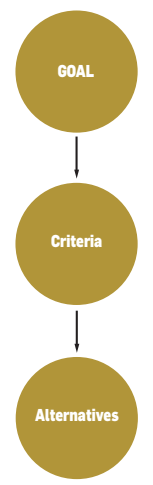

(a)

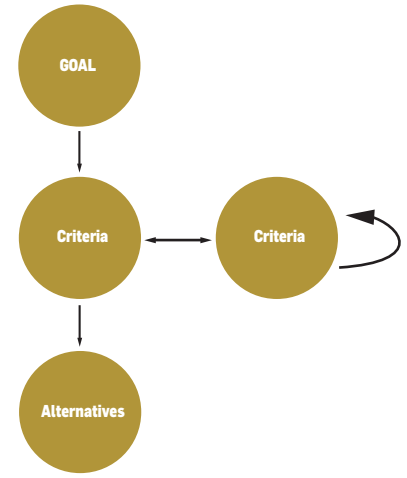

(b)

A supermatrix is in fact a partitioned matrix in which each part of the matrix shows the relationship between two nodes (decision levels) in the whole decision problem. The standard form of a supermatrix introduced by Saaty (1996) is described as follows, where $C$ denotes the nodes and $e$ represent the elements within nodes (see Figure B2). The $W$ vectors within the matrix represent weighted vectors resulting from pairwise comparisons of the elements within nodes.

\section{Figure B2. Supermatrix}

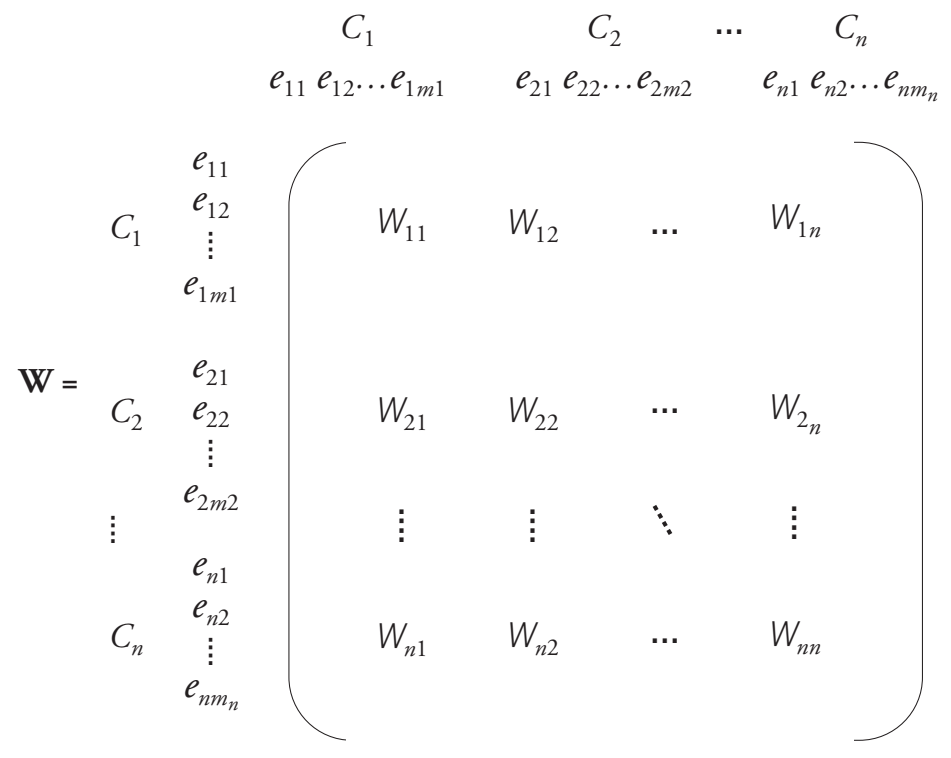

All the relationships and interactions between the elements of decision levels are evaluated by pairwise comparisons in the supermatrix method. However, when 
entering pairwise comparisons made between the elements of decision levels into the supermatrix, the sum of columns often exceeds 1, which is called unweighted supermatrix. By multiplying the weight of each cluster by their corresponding elements, the weighted supermatrix is obtained. Finally, to achieve the final weight of the problem alternatives, the decision criteria and problem solving, the limited supermatrix should be calculated. Using probabilistic matrices and Markov chains, Saaty proves that the final weight of elements is obtained from the equation B1:

$$
\mathbf{W}=\lim _{k \rightarrow \infty} \quad W^{2 k-1},
$$

where, Saaty notes, $W$ is the limited supermatrix, $\mathbf{W}$ is the weighted supermatrix and $k$ denotes as an arbitrary number.

In the ANP, the consistency principle must also be considered. Knowledge about the consistency of judgments is important because judgments must not be randomly applied. The Consistency Rate $(C R)$ in the ANP is calculated according to the formula presented by Saaty (1996) (equation B2). It is difficult to achieve full consistency, so if this rate is less than 0.1 , pairwise comparisons data can be trusted:

$$
C R=\sum_{\substack{\text { Control } \\ \text { criteria }}} K_{\text {Control }} \sum_{\substack{\text { critia } \\ \text { All } \\ \text { chains }}}\left(\sum_{j=1}^{h} \sum_{i=1}^{n_{i j+1}} W_{i j} \mu_{i, j+1}\right)+\sum_{\substack{\text { Control } \\ \text { criteria }}} K_{\text {Control }} \sum_{\text {criteria }}^{h} \sum_{j=1}^{h} \sum_{i=1}^{n_{i j+1}} W_{i k} \sum_{h=1}^{|c h|} W_{(k)(b)} \mu_{k}(j, h),
$$

where:

$n_{j}$ is the number of elements in $j$ th level of hierarchy/cluster, $j=1,2, \ldots h$;

$w_{i j}$ is the weight of ith criteria in the $j$ th level/cluster;

$n_{i, j+1}$ is the number of elements in $j+1$ th level of hierarchy/cluster;

$\mu_{i, j+1}$ is the consistency rate in $j+1$ th level of hierarchy/cluster;

$K_{\text {Control criteria }}$ is the weight of control criteria;

$w_{(k)(h)}$ is the weighted priority of influence of $h$ th cluster on $k$ th cluster;

$n_{k}$ is the number of elements in $k$ th cluster, $k=1,2, \ldots, s$;

$w_{j k}$ is the limited priority of $j$ th element in kth element;

$\mu_{k}(j, h)$ is the consistency rate of the elements of $h$ th cluster.

This method is shown as follows (Lin et al., 2008; Tsai and Chou, 2009):

Step 1: Definition of policy issues and establishment of policy-making members.

Step 2: Construction of network hierarchy layer structure of the problems.

Step 3: Questionnaire surveys and expert preference integration.

Step 4: Establishment of comparison matrices.

Step 5: Consistency test.

Step 6: Computations of supermatrix.

Step 7: Selection of optimal options. 


\section{Appendix C. Overview of the DEMATEL method}

In a totally interdependent system, all criteria of the systems are mutually related, directly or indirectly; thus, any interference with one of the criteria affects all the others so it is difficult to find priorities for action (Tzeng et al., 2007).

The DEMATEL method is a comprehensive method for building and analyzing a structural model involving causal relationships between complex factors (Wu, 2008) which can convert the relationship between the causes and effects of criteria into an intelligible structural model of the system (Tsai and Chou, 2009). The DEMATEL method was first introduced in Geneva Research Center. The method was used to solve complex problems relating to issues such as famine, energy, environmental protection, etc. (Wang et al., 2007).

This technique, which is one of the varieties of decision-making method, has been developed with the belief that proper application of scientific research methods can improve the complicated structure of problems and contribute to the identification of scientific solutions using AHP (Trevithick et al., 2003; Tzeng et al., 2010). Based on pairwise comparisons, the DEMATEL provides a hierarchical structure of factors in a system showing their mutual impact and influence relationships. This structure is created by using experts' opinions on the extraction of a system's factors and the principles of graph theory in such a way that the intensity of their influence is quantitatively determined (Lin and Wu, 2008).

This method is shown as follows:

1. Producing the direct-relation matrix: A group of $m$ experts and $n$ factors are used in this step. Each expert is asked to view the degree of direct influence between two factors based on pairwise comparison. The result of comparison produces the direct-relation matrix $\mathbf{Z}$.

2. Normalizing the direct-relation matrix: The normalized direct-relation matrix $\mathbf{X}$ is obtained as in ( $C 1)$, where value of each element in the matrix is ranged between $[0,1]$.

$$
\mathbf{X}=s \times \mathbf{Z}
$$

where

$$
s=\min \left[\frac{1}{\max \sum_{j=1}^{n}\left|z_{i j}\right|}, \frac{1}{\max \sum_{i=1}^{n}\left|z_{i j}\right|}\right], \quad i, j=1,2, \ldots ., n .
$$


3. Attaining the total-relation matrix: The total-relation matrix $\mathbf{T}$ is obtained by utilizing equation (C2), in which $\mathbf{I}$ is the identity matrix.

$$
\mathbf{T}=\mathbf{X}(\mathbf{I}-\mathbf{X})^{-1}
$$

4. Calculating the sums of rows and columns of matrix $\mathbf{T}$ : The sum of rows and the sum of columns are separately denoted as vector $\mathbf{D}$ and vector $\mathbf{R}$ through formulas (C3), (C4) and (C5). Here, $d_{i}$ is the sum of each row in $\mathbf{T}$ and the rows show the degrees of direct and indirect impacts on the other criteria, and $r_{j}$ is the sum of each column in $\mathbf{T}$, where columns indicates the degrees of influences from other criteria. Numeric algorithm variable $d_{i}$, therefore, represents the factors that influence others, $r_{j}$ represents factors that are influenced by others, $d_{i}+r_{j}$ represents the strength of relationships between factors, $d_{i}-r_{j}$ represents the strength of influences among factors. In other words, $d_{i}+r_{j}$ and $d_{i}-r_{j}$ represent the so called prominences and relations, respectively (Lee et al., 2011).

$$
\begin{aligned}
& \mathbf{T}=\left[t_{i j}\right]_{n \times n}, \quad i, j=1,2, \ldots ., n \\
& \mathbf{D}=\left[\sum_{j=1}^{n} t_{i j}\right]_{n \times 1}=\left[t_{i .}\right]_{n \times 1} \\
& \mathbf{R}=\left[\sum_{i=1}^{n} t_{i j}\right]_{1 \times n}^{t}=\left[t_{. j}\right]_{n \times 1}
\end{aligned}
$$

5. Obtaining the inner dependence matrix: In this step, the sum of each column in total-relation matrix is made equal to 1 by the normalization method, and then the inner dependence matrix can be acquired.

Before forming the unweighted supermatrix, DEMATEL allows us to deal with inner dependences. In theory this can be done with ANP but DEMATEL offers a practical alternative. This is because the DEMATEL can produce more valuable information for making decisions (Wu, 2008).

In this paper, by normalizing the total-relation matrix $\mathbf{T}$ (DEMATEL) and combining it with the unweighted supermatrix (ANP), we study and analyze approaches, criteria and sub-criteria and calculate their weights. 
